\title{
Performance Prediction of Compressible Two-Phase Flow through Ejectors
}

\author{
Hewedy N.I.I., Hamed M.H., Mahrous A.F.M. , Ghonim T.A. \\ Mechanical Power Engineering Department, \\ Faculty of Engineering, Menoufiya University, \\ Shebin El-Kom, Egypt.
}

\begin{abstract}
The objective of present work is to investigate theoretically the performance of two-phase flow (gas-liquid) through ejectors. The numerical investigation is based on non-homogeneous, (liquid and vapor velocities are not equal), non-equilibrium (liquid and vapor temperatures are not equal), two-fluid model, (Eulerian-Eulerian), conservation equations governing steady, two-dimensional (axisymmetric), turbulent, compressible, and parabolic two-phase flow. These equations are namely continuity, momentum, and energy. These equations are solved iteratively using control volume method with Prandtl's mixing length as a turbulence model. Mass and heat transfer between the liquid and vapor phases are considered. Wall function is used instead of using very fine grid near the wall. The coordinates system is converted to bodyfitted coordinates. Refrigerant 134a is used as a working fluid. The Modified Benedict-Webb-Rubin (MBWR) equation of state is used to represent compressibility. The presented model is validated against previously published data in literature. The validation showed reasonable agreement. Effects of changes in geometry and operating conditions on ejector performance are investigated. Moreover, effects of certain parameters on ejector efficiency are presented showing that, for maximum efficiency both geometrical and operational parameters must be carefully selected. Overall, the results lead to useful information for ejector optimum design and prediction of the ejector behavior and performance.

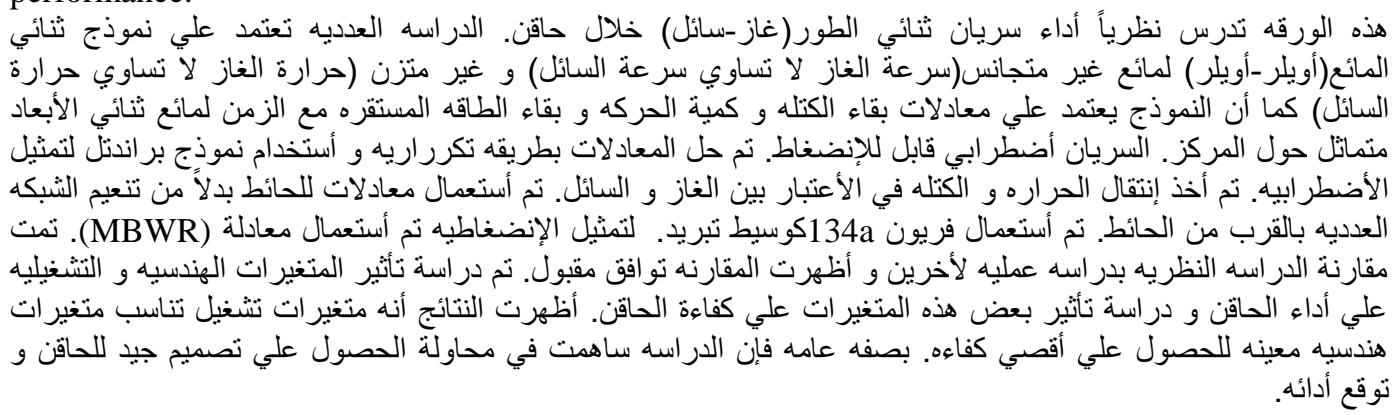

Keywords: Non-homogeneous, non-equilibrium, two-phase flow, mass and heat transfer, compressible flow, two-fluid model, maximum efficiency.

\section{INTRODUCTION}

Ejectors are used in several engineering applications, such as steam power plants, cooling nuclear systems, mixing processes and refrigeration systems, because they have many advantages over conventional compression systems. These include no moving parts and hence no lubrication is needed. The relatively low capital cost, simplicity of operation, reliability and very low maintenance cost are other advantages. The major drawback is the low efficiency. The ejector, employed as a fluid pumping device, represents a well-known technology for industrial refrigeration in order to reduce the required compressor work.

Several theoretical and experimental studies have been performed in order to understand the fundamental mechanisms of ejector operation. From the survey of literatures [1-4], ejectors were designed and analyzed based on a classical theory based on one-dimensional assumptions. Despite their usefulness, these studies suffer from the limitative nature of the assumptions, such as that the velocities of both primary and secondary flows are uniformly distributed in the radial direction, on which they are based, preventing a detailed study of flow evolution 
along the ejector, or accounting for possible phase changes during the compression process. Yinhai et al. [5] employed a computational fluid dynamics (CFD) technique using FLUENT 6.2 to investigate the effect of two important ejector geometry parameters: the primary nozzle exit position (NXP) and the mixing section converging angle, on its performance. The optimum NXP was proportional to the mixing section throat diameter and it increased as the primary flow pressure increased. As for the converging angle of mixing section, the ejector performance was found to be very sensitive to it. Rogdakis and Alexis [6] investigated theoretically the ejector design when it is inserted between the separator-condenser and evaporator in an ammonia-water combined ejectorabsorption cycle. It was observed that for any set of pressures (primary flow inlet pressure, secondary flow inlet pressure and ejector exit pressure) there is a maximum value of the flow entrainment ratio. This value and the corresponding operating conditions for the optimum design of the ejector are provided. In this study, for every optimum operating condition (maximum entrainment), the area ratio is estimated. Sriveerakul et al. [7] investigated the use of CFD (FLUENT) in predicting the performance of a steam ejector used in refrigeration applications. The effects of operating conditions and geometries on ejector performance were investigated. The CFD perditions included static pressure distributions at different entrainment ratios and different back pressures. Elbel and Hrnjak [8] presented an experimental validation of a prototype ejector designed to reduce throttling losses encountered in a transcritical R744 system operation. Their experiments were analyzed to quantitatively assess the effects on system performance as a result of changes in basic ejector dimensions such as motive nozzle and diffuser sizing. Their results confirmed that like in a conventional transcritical R744 system with expansion valve, the high-side pressure control integrated into the ejector could be used to maximize the system performance. An ejector efficiency based on standard pressure, temperature, and mass flow rate measurements was defined. Their results showed also that the ejector performed with a higher efficiency when the high-side pressure was relatively low. However, it was also found experimentally that despite lower ejector efficiencies, the COP increased as the higher pressure side increased as a result of using the integrated needle to reduce the motive nozzle throat area in the ejector.

Dvorak and Safarik [9] studied experimentally and numerically supersonic and transonic flow past a two-dimensional model ejector. Numerical results were obtained by means of both the straight solution of shock waves in supersonic flow using classical relations of parameters of shock waves and the FLUENT 6 program. The influences of back pressure

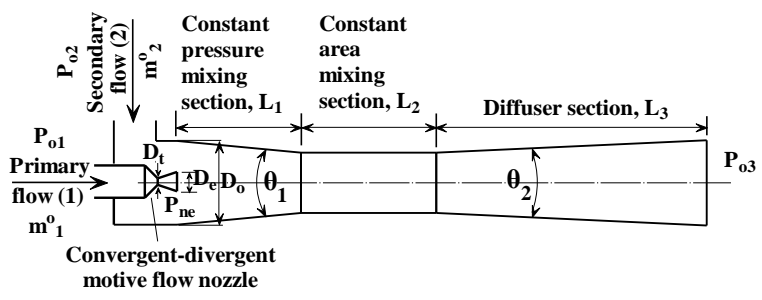

Fig. (1) Ejector geometry

and pressure of primary flow on ejector performance and on supersonic flow structure were investigated. It was concluded that the ejector performance does not depend on the back pressure in the case of supersonic flow in some extent. More recently, Reddick et al. [11] studied experimentally the possibility of improving the energy efficiency of a vapor compression refrigeration system where a two-phase ejector replaces the expansion valve. In their study a test rig using refrigerant R134a was designed and built which functions in both the conventional mode and in ejector mode. Their experimental results showed an improvement of $11 \%$ in the coefficient of performance (COP) in ejector mode as compared with that of the conventional mode. McGoverna et al. [12] developed a significant simple 1-D numerical model and experimental analysis to understand the variety of flow regimes present in steady flow ejectors. In particular, the entrainment ratio was seen to be highest when the entrained fluid reached a choked condition at the entrance to the constant area mixing section region. In addition, rather than focusing upon the maximization of efficiency, they searched for operational conditions that maximize ejector efficiency. Despite the remarkable progress that has been achieved, and due to the flow complexity resulting from simultaneous interaction of numerous parameters, ejector modeling remains a problem that has yet to be resolved because one of the main difficulties still to overcome, is a reliable numerical representation of the mixing process between the primary and secondary streams.

Recent studies have shown that performance of an ejector cycle largely depended on two types of parameters. First: the geometrical parameters, as shown in Fig. (1), include three lengths, two angles and two area ratios. Second: the operational parameters which include the mass flow ratio, nozzle expansion pressure ratio, ejector compression ratio, temperature ratio and stagnation pressure coefficient. In order to assess the ejector performance, ejector efficiency [8], as illustrated in Fig. (2), is used. Since both operation conditions and geometries significantly affect performance of the ejector, a deep understanding of ejector working principle, mixing process and entrainment feature is essential to improve its efficiency. Information on ejector design and performance predictions is of utmost importance. Such information can be obtained through modeling. This paper is an attempt to represent the operation of 
an ejector more accurately by means of a numerical model that better accounts for changes in refrigerant properties with the flow axial and radial positions. The model developed on this basis is then applied to examine the effects of different parameters on ejector performance.

$\eta=\left(\frac{\mathrm{m}_{2}^{\mathrm{o}}}{\mathrm{m}_{1}^{\mathrm{o}}}\right)\left(\frac{\mathrm{h}_{2^{\prime}, \text { is }}-\mathrm{h}_{\mathrm{o} 2}}{\mathrm{~h}_{\mathrm{o} 1}-\mathrm{h}_{1^{\prime}, \text { is }}}\right)=\varepsilon \frac{\mathrm{h}_{2^{\prime}, \text { is }}-\mathrm{h}_{\mathrm{o} 2}}{\mathrm{~h}_{\mathrm{o} 1}-\mathrm{h}_{1^{\prime}, \text { is }}}$

\section{2- MATHEMATICAL MODEL}

A non-homogeneous, non-equilibrium, twofluid model (Eulerian-Eulerian) conservation equations are presented below based on several basic assumptions [13]:

- two-dimensional, axisymmetric and steady flow,

- turbulent and compressible flow,

- mass and heat transfer are considered,

- parabolic flow,

- the fluid is Newtonian,

- gravitational effects are negligible,

- adiabatic ejector walls, and

- dispersed droplet flow assuming that the ratio of liquid void (volume) fraction to droplet diameter is constant.

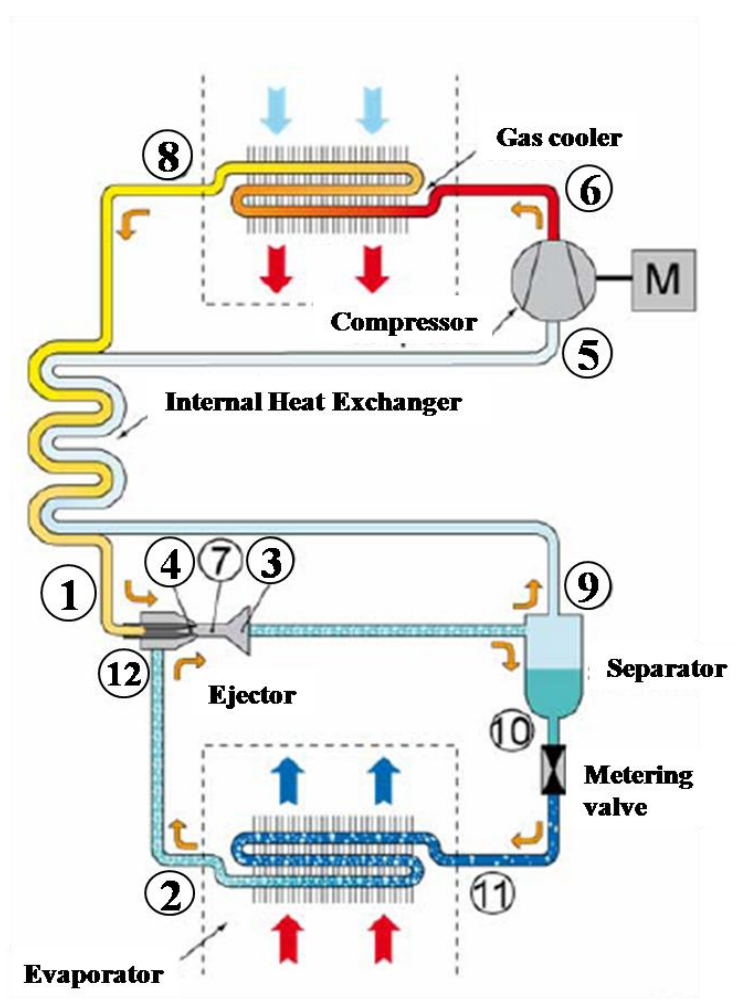

a) Layout

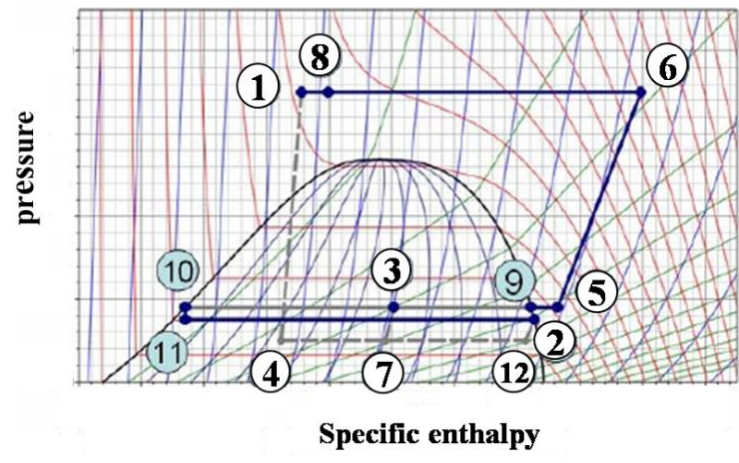

b) P-h diagram of the ejector cycle

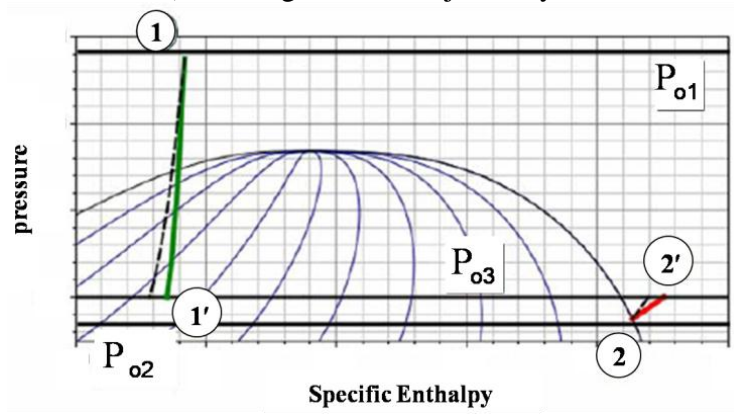

c) P-h diagram showing three pressures

Fig. (2): Ejector refrigeration cycle

\subsection{Governing Equations}

The conservation of mass for two-phase flow in axisymmetric coordinates is:

$\frac{\partial}{\partial \mathrm{x}}(\mathrm{ur} \rho \alpha)+\frac{\partial}{\partial \mathrm{r}}(\operatorname{vr} \rho \alpha)=\mathrm{r} \Gamma$

The conservation of axial and radial momentum in axisymmetric coordinates is:

$$
\begin{gathered}
\frac{\partial}{\partial \mathrm{x}}\left(\alpha \mathrm{r} \rho \mathrm{u}^{2}\right)+\frac{\partial}{\partial \mathrm{r}}(\operatorname{vr} \rho \mathrm{u} \alpha)=-\alpha \frac{\partial}{\partial \mathrm{x}}(\mathrm{rP}) \\
+\frac{\partial}{\partial \mathrm{r}}\left(\mathrm{r} \alpha \mu \frac{\partial \mathrm{u}}{\partial \mathrm{r}}\right)+\mathrm{r}_{\mathrm{x}}+\mathrm{r}_{\mathrm{x}} \\
\frac{\partial}{\partial \mathrm{r}}\left(\mathrm{r} \alpha \rho \mathrm{v}^{2}\right)+\frac{\partial}{\partial \mathrm{x}}(\mathrm{r} \rho \alpha \mathrm{uv})=-\mathrm{r} \alpha \frac{\partial \mathrm{P}}{\partial \mathrm{r}}+\left(2 \mathrm{r} \alpha \mu \frac{\partial \mathrm{v}}{\partial \mathrm{r}}\right) \\
+\frac{\partial}{\partial \mathrm{x}}\left(\mathrm{r} \alpha \mu \frac{\partial \mathrm{u}}{\partial \mathrm{r}}\right)-\frac{2 \alpha \mu \mathrm{v}}{\mathrm{r}}+\mathrm{r}_{\mathrm{r}}+\mathrm{r}_{\mathrm{r}}
\end{gathered}
$$

In addition,

$\alpha \frac{\partial \mathrm{P}}{\partial \mathrm{x}}=\frac{\partial}{\partial \mathrm{x}}(\alpha \mathrm{P})-\mathrm{P} \frac{\partial \alpha}{\partial \mathrm{x}}$

The conservation of energy in axisymmetric coordinates is:

$$
\begin{aligned}
& \frac{\partial}{\partial \mathrm{r}}(\mathrm{r} \alpha \rho \mathrm{vT})+\frac{\partial}{\partial \mathrm{x}}(\mathrm{r} \alpha \rho \mathrm{uT})=\frac{1}{\mathrm{c}_{\mathrm{p}}} \frac{\partial}{\partial \mathrm{r}}\left(\mathrm{rk} \alpha \frac{\partial \mathrm{T}}{\partial \mathrm{r}}\right) \\
& +\frac{\beta \mathrm{T}}{\mathrm{c}_{\mathrm{p}}}\left(\mathrm{ur} \alpha \frac{\mathrm{dP}}{\mathrm{dx}}\right)+\frac{\mathrm{r}}{\mathrm{c}_{\mathrm{p}}}\left(\mathrm{E}_{\mathrm{ht}}+\mathrm{E}_{\mathrm{mt}}+\mathrm{E}_{\mathrm{ke}}+\mathrm{E}_{\mathrm{wt}}\right)
\end{aligned}
$$

While the radial momentum is indeed small compared to the axial momentum, this equation still needs to be solved because an additional unknown, 
the volume (void) fraction, is present in the twophase flow. In order to obtain the radial distribution of void fraction, the radial momentum equation must be solved.

\subsection{Nondimensionalization}

Equations (2), (3), (4) and (6) can be expressed in a dimensionless form through the following dimensionless parameters.

$$
\begin{aligned}
& \mathrm{x}^{*}=\frac{\mathrm{x}}{\mathrm{r}_{\mathrm{o}}}, \mathrm{r}^{*}=\frac{\mathrm{r}}{\mathrm{r}_{\mathrm{o}}}, \mathrm{u}^{*}=\frac{\mathrm{u}}{\mathrm{u}_{\mathrm{o}}}, \mathrm{v}^{*}=\frac{\mathrm{v}}{\mathrm{u}_{\mathrm{o}}}, \mathrm{p}^{*}=\frac{\mathrm{P}-\mathrm{P}_{\mathrm{o}}}{\rho_{\mathrm{o}} \mathrm{u}_{\mathrm{o}}^{2}} \\
& \mathrm{~T}^{*}=\frac{\mathrm{T}}{\mathrm{T}_{\mathrm{o}}}, \rho^{*}=\frac{\rho}{\rho_{\mathrm{o}}}, \mu^{*}=\frac{\mu}{\mu_{\mathrm{o}}}, \mathrm{c}_{\mathrm{p}}{ }^{*}=\frac{\mathrm{c}_{\mathrm{p}}}{\mathrm{c}_{\mathrm{p}, \mathrm{o}}}, \mathrm{k}^{*}=\frac{\mathrm{k}}{\mathrm{k}_{\mathrm{o}}} \\
& \beta^{*}=\frac{\beta}{1 / \mathrm{T}_{\mathrm{o}}}, \Gamma^{*}=\Gamma \frac{\mathrm{r}_{\mathrm{o}}}{\rho_{\mathrm{o}} \mathrm{u}_{\mathrm{o}}}, \mathrm{F}^{*}=\mathrm{F} \frac{\mathrm{r}_{\mathrm{o}}}{\rho_{\mathrm{o}} \mathrm{u}_{\mathrm{o}}^{2}} \\
& \mathrm{M}^{*}=\mathrm{M} \frac{\mathrm{r}_{\mathrm{o}}}{\rho_{\mathrm{o}} \mathrm{u}_{\mathrm{o}}^{2}}, \mathrm{E}^{*}=\mathrm{E} \frac{\mathrm{r}_{\mathrm{o}}}{\mathrm{c}_{\mathrm{p}, \mathrm{o}} \mathrm{T}_{\mathrm{o}} \rho_{\mathrm{o}} \mathrm{u}_{\mathrm{o}}}, R e=\frac{\mathrm{r}_{\mathrm{o}} \rho_{\mathrm{o}} \mathrm{u}_{\mathrm{o}}}{\mu_{\mathrm{o}}} \\
& \operatorname{Pr}=\frac{\mu_{\mathrm{o}} \mathrm{c}_{\mathrm{p}, \mathrm{o}}}{\mathrm{k}_{\mathrm{o}}}, E c=\frac{\mathrm{u}_{\mathrm{o}}^{2}}{\mathrm{~T}_{\mathrm{o}} \mathrm{c}_{\mathrm{p}, \mathrm{o}}}, \frac{\partial}{\partial \mathrm{x}}=\frac{1}{\mathrm{r}_{\mathrm{o}}} \frac{\partial}{\partial \mathrm{x}^{*}}, \frac{\partial}{\partial \mathrm{r}}=\frac{1}{\mathrm{r}_{\mathrm{o}}} \frac{\partial}{\partial \mathrm{r}^{*}}
\end{aligned}
$$

Here, values with the o subscript represent a reference at some location in the flow, generally liquid values at the primary flow nozzle exit section.

The equations after substitution and simplifications are respectively:

$$
\begin{gathered}
\frac{\partial}{\partial \mathrm{x}^{*}}\left(\mathrm{r}^{*} \rho^{*} \alpha \mathrm{u}^{*}\right)+\frac{\partial}{\partial \mathrm{r}^{*}}\left(\mathrm{r}^{*} \rho^{*} \alpha \mathrm{v}^{*}\right)=\mathrm{r}^{*} \Gamma^{*} \\
\frac{\partial}{\partial \mathrm{x}^{*}}\left(\mathrm{r}^{*} \rho^{*} \alpha \mathrm{u}^{* 2}\right)+\frac{\partial}{\partial \mathrm{r}^{*}}\left(\mathrm{r}^{*} \rho^{*} \alpha \mathrm{u}^{*} \mathrm{v}^{*}\right)=-\alpha \frac{\partial\left(\mathrm{r}^{*} \mathrm{P}^{*}\right)}{\partial \mathrm{x}^{*}} \\
+\frac{\partial}{\partial \mathrm{r}^{*}}\left(\frac{\mathrm{r}^{*} \alpha \mu^{*}}{\operatorname{Re}} \frac{\partial \mathrm{u}^{*}}{\partial \mathrm{r}^{*}}\right)+\mathrm{r}^{*} \mathrm{~F}_{\mathrm{x}}^{*}+\mathrm{r}^{*} \mathrm{M}_{\mathrm{x}}^{*} \\
\frac{\partial}{\partial \mathrm{r}^{*}}\left(\mathrm{r}^{*} \rho^{*} \alpha \mathrm{v}^{* 2}\right)+\frac{\partial}{\partial \mathrm{x}^{*}}\left(\mathrm{r}^{*} \rho^{*} \alpha \mathrm{u}^{*} \mathrm{v}^{*}\right)=\frac{\partial}{\partial \mathrm{r}^{*}}\left(\frac{2 \mathrm{r}^{*} \alpha \mu^{*}}{\operatorname{Re}} \frac{\partial \mathrm{v}^{*}}{\partial \mathrm{r}^{*}}\right) \\
-\mathrm{r}^{*} \alpha \frac{\partial \mathrm{P}^{*}}{\partial \mathrm{r}^{*}}+\frac{\partial}{\partial \mathrm{x}^{*}}\left(\frac{\mathrm{r}^{*} \alpha \mu^{*}}{\operatorname{Re}} \frac{\partial \mathrm{u}^{*}}{\partial \mathrm{r}^{*}}\right)-\frac{2 \mu^{*} \alpha \mathrm{v}^{*}}{\operatorname{Re} \mathrm{r}^{*}}+\mathrm{r}^{*} \mathrm{~F}_{\mathrm{r}}^{*}+\mathrm{r}^{*} \mathrm{M}_{\mathrm{r}}^{*} \\
\frac{\partial}{\partial \mathrm{r}^{*}}\left(\mathrm{r}^{*} \alpha \rho^{*} \mathrm{v}^{*} \mathrm{~T}^{*}\right)+\frac{\partial}{\partial \mathrm{x}^{*}}\left(\mathrm{r}^{*} \alpha \rho^{*} \mathrm{u}^{*} \mathrm{~T}^{*}\right)=\frac{E c \beta^{*} \mathrm{~T}^{*} \mathrm{r}^{*} \mathrm{u}^{*} \alpha}{\mathrm{c}_{\mathrm{p}}} \frac{\partial \mathrm{P}^{*}}{\partial \mathrm{x}^{*}} \\
+\frac{1}{\mathrm{c}_{\mathrm{p}}^{*}} \frac{\partial}{\partial \mathrm{r}^{*}}\left(\frac{\mathrm{r}^{*} \alpha \mathrm{k}^{*}}{\operatorname{Re} \operatorname{Pr}} \frac{\partial \mathrm{T}^{*}}{\partial \mathrm{r}^{*}}\right)+\frac{\mathrm{r}^{*}}{\mathrm{c}_{\mathrm{p}}^{*}}\left[\mathrm{E}_{\mathrm{ht}}^{*}+\mathrm{E}_{\mathrm{mt}}^{*}+\mathrm{E}_{\mathrm{ke}}^{*}+\mathrm{E}_{\mathrm{wt}}^{*}\right]
\end{gathered}
$$

\subsection{Momentum Transfer}

Momentum transfer results from unequal velocities between the two phases. A simple model is proposed in which the interfacial drag force depends on a drag coefficient as given by [13]:

$$
\mathrm{F}=\frac{3 \rho_{\mathrm{V}} \mathrm{C}_{\mathrm{D}}}{4}\left(\frac{\alpha_{\mathrm{L}}}{2 \mathrm{r}_{\mathrm{d}}}\right)\left|\overrightarrow{\mathrm{V}}_{\text {other }}-\overrightarrow{\mathrm{V}}\right|\left(\mathrm{u}_{\text {other }}-\mathrm{u}\right)
$$

The velocity difference between the phases is broken up using the absolute value sign as shown to ensure that the drag force is positive on the slower moving phase and negative on the faster moving phase. It is assumed that the droplets are small enough to be nearly spherical. A formula for $C_{D}$ is given by [13]:

$$
\mathrm{C}_{\mathrm{D}}=\frac{24\left(1+0.1 \mathrm{Re}_{\mathrm{int}}^{0.75}\right)}{\mathrm{Re}_{\mathrm{int}}}
$$

Where,

$$
\begin{aligned}
& \operatorname{Re}_{\text {int }}=\frac{2 r_{d} \rho_{\mathrm{V}} V_{\mathrm{r}}}{\mu_{\mathrm{m}}} \\
& \mathrm{V}_{\mathrm{r}}=\sqrt{\left(\mathrm{u}_{\mathrm{L}}-\mathrm{u}_{\mathrm{V}}\right)^{2}+\left(\mathrm{v}_{\mathrm{L}}-\mathrm{v}_{\mathrm{V}}\right)^{2}}
\end{aligned}
$$

The mixture viscosity, $\mu_{\mathrm{m}}$ is given by [14]:

$\mu_{\mathrm{m}}=\left(\frac{\mathrm{X}}{\mu_{\mathrm{v}}}+\frac{1-\mathrm{X}}{\mu_{\mathrm{L}}}\right)^{-1}$

The formula for momentum transferred between phases due to evaporation or condensation is given by:

$$
\mathrm{Mx}=\operatorname{MAX}[\Gamma, 0] \mathrm{u}_{\mathrm{other}}-\mathrm{MAX}[-\Gamma, 0] \mathrm{u}
$$

It is noted that positive $\Gamma$, which means mass is being added to a phase $i$, corresponds to a positive addition of momentum. However momentum gained by one phase through evaporation or condensation is lost equally by the other phase.

\subsection{Boundary Conditions}

Along the axis of symmetry as shown in Fig. (3), the following boundary conditions are used:

$\left(\frac{\partial \mathrm{u}}{\partial \mathrm{r}}\right)_{\mathrm{symm}}=0, \quad \mathrm{v}_{\mathrm{symm}}=0, \quad\left(\frac{\partial \mathrm{T}}{\partial \mathrm{r}}\right)_{\text {symm }}=0$

And the adiabatic wall boundary conditions are:

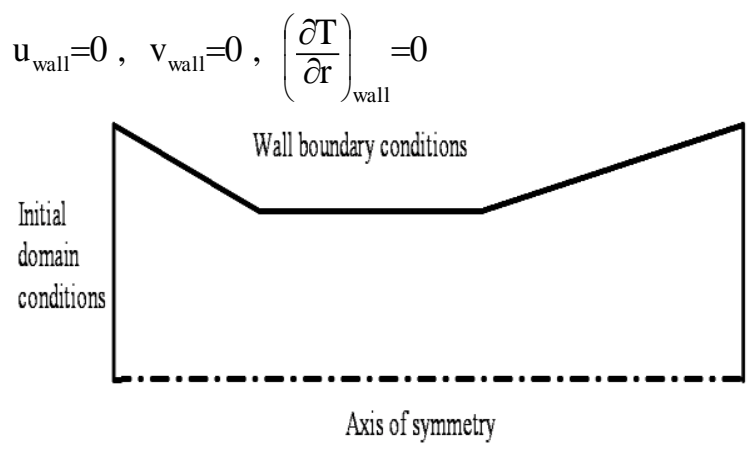

Fig. (3): Boundary conditions for parabolic flow problem

\subsection{Mass and Heat Transfer}

The interfacial mass transfer, $\Gamma$ can be found by relating the boiling heat transfer to the latent heat of evaporation of the fluid by [13]:

$$
\Gamma= \pm \frac{E_{h t, L}-E_{h t, \mathrm{~V}}}{h_{f g}}
$$

Where, $E_{h t}$ is the heat transfer rate (either conduction or convection) between interfacial surface and the bulk phase, as shown in Fig. (4), which is given by:

$$
\mathrm{Eht}_{\mathrm{L}}=\mathrm{h}_{\mathrm{L}}\left(\mathrm{Ts}-\mathrm{T}_{\mathrm{L}}\right)\left(\frac{6 \alpha_{\mathrm{L}}}{2 \mathrm{r}_{\mathrm{d}}}\right)
$$




$$
E h t, v=h_{v}(T v-T s)\left(\frac{6 \alpha_{L}}{2 r_{d}}\right)
$$

The last term in parenthesis in Eqns. (18) and (19) represents the surface area of each droplet times number of particles per control volume, as required to ensure consistent units.

The sign and magnitude of the heat transfer terms for liquid $\left(E_{h t, L}\right)$ and vapor $\left(E_{h t, V}\right)$ are important to determine whether evaporation or condensation occur. In general, if the net heat transfer to the interface is positive (i.e. negative $\left.E_{h t, L}-E_{h t, V}\right)$, evaporation takes place and if the net heat transfer to the interface is negative (i.e. positive $E_{h t, L^{-}} E_{h t, V}$ ), condensation takes place.

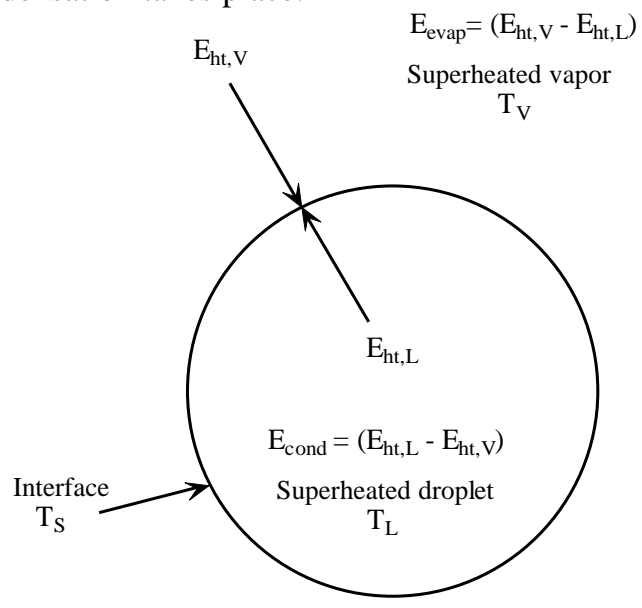

Fig. (4) Energy balance on a droplet, [13].

Interfacial heat and mass transfer are strongly coupled. Interfacial heat transfer occurs when the liquid and vapor phases are at unequal temperatures. Considering heat balance of a liquid droplet in vapor flow, the interface itself is at the saturation temperature so conduction between it and the liquid phase as well as convection between it and the vapor phase occurs. Since the interface cannot store energy, the sum of all heat fluxes to it must equal zero. Thus any imbalance between conduction and convection is made up for by evaporation or condensation, which is the interfacial mass transfer.

Solbrig et al. [15] model includes methods to find the heat transfer coefficient, $\mathrm{h}$, for various combinations of conduction and convection. For a dispersed liquid droplet flow in a continuous vapor phase, the heat transfer coefficient for conduction to the liquid droplet, $\mathrm{h}_{\mathrm{L}}$, is given by:

$$
\mathrm{h}_{\mathrm{L}}=8.067 \frac{\mathrm{K}_{\mathrm{L}}}{\mathrm{r}_{\mathrm{d}}}
$$

While, the heat transfer coefficient for convection, $\mathrm{h}_{\mathrm{V}}$, in the continuous gas phase is given by:

$$
\mathrm{h}_{\mathrm{v}}=\frac{1}{\mathrm{r}_{\mathrm{d}}}\left[1+0.37 \overline{\mathrm{R}} \mathrm{e}^{0.25} \overline{\mathrm{Pr}}_{\mathrm{v}}{ }^{0.33}\right]
$$

Where, $\quad \overline{\mathrm{R}} \mathrm{e}=\frac{2 \rho_{\mathrm{v}}\left|\mathrm{u}_{\mathrm{L}}-\mathrm{u}_{\mathrm{v}}\right| \mathrm{r}_{\mathrm{d}}}{\mu_{\mathrm{v}}}$, and

$\mathrm{K}_{\mathrm{L}}$ is the thermal conductivity for liquid.

While, the interfacial thermal energy transferred (sensible heat) due to mass transfer (evaporation or condensation), $\mathrm{E}_{\mathrm{m}}$, is given by:

$$
\mathrm{E}_{\mathrm{mt}}=\mathrm{C}_{\mathrm{p}} \mathrm{T} \Gamma
$$

The kinetic energy transferred due to mass transfer, $\mathrm{E}_{\mathrm{ke}}$, is given by:

$$
\mathrm{E}_{\mathrm{ke}}=\operatorname{MAX}[\Gamma, 0]\left(\frac{1}{2} \mathrm{u}_{\text {other }}^{2}+\frac{1}{2} \mathrm{u}^{2}-\mathrm{uu}_{\text {other }}\right)
$$

This term is actually viscous dissipation. Since the phases generally move at unequal velocities, any mass transferred between them must equilibrate to the new phase's velocity, an effect which results in dissipation. The dissipation is assumed to always be in the phase to which mass is added.

The viscous dissipation produced by work of the interfacial drag force, $\mathrm{E}_{\mathrm{wt}}$, is given by:

$$
\mathrm{E}_{\mathrm{wt}}=\frac{1}{2}\left(\mathrm{u}_{\text {other }}-\mathrm{u}\right) \mathrm{F}
$$

This term is always positive because when the velocity difference is positive the interfacial drag force is also positive. Conversely, when the velocity difference is negative the drag force is also negative. The factor of $1 / 2$ assumes that each phase receives an equal share of the total dissipation.

\subsection{Droplet Size}

An empirical formula [14] states that the maximum droplet diameter, $d_{\max }$ is governed by a critical Weber number, $\mathrm{We}_{\mathrm{cr}}$ which is the ratio of forces tending to break up the particle (turbulent fluctuations) to the force which keeps it together (surface tension):

$$
\begin{aligned}
& \mathrm{d}_{\max }=1.38 \frac{\left(\sigma \mathrm{We}_{\mathrm{cr}}\right)^{0.6}}{\rho_{\mathrm{L}}^{0.2} \mu_{\mathrm{V}}^{0.1} \rho_{\mathrm{V}}^{0.3}} \frac{\mathrm{D}^{0.5}}{\nu_{\mathrm{V}}^{1.1}} \\
& \mathrm{We}_{\mathrm{cr}}=\frac{\rho_{\mathrm{V}} \nu_{\mathrm{V}^{2}}}{\left(\sigma / \mathrm{d}_{\text {max }}\right)}\left(\frac{\rho_{\mathrm{L}}}{\rho_{\mathrm{V}}}\right)^{1 / 3}
\end{aligned}
$$

Where $v_{\mathrm{v}}$ here is the average fluctuating velocity of the turbulent dispersion. A value of 1.1 , which is used in this work, is obtained formerly experimentally by Cramers $e t$ al. [16] for the critical Weber number. However, the mean droplet diameter is found experimentally to be approximately $62 \%$ of the maximum droplet diameter [17].

\subsection{Turbulence Modeling}

Prandtl's mixing length turbulence model [13] with wall function is used. The Boussinesq assumption is inherent, in which all the effects of turbulence can be incorporated into a single turbulent viscosity. The turbulent viscosity is simply added to 


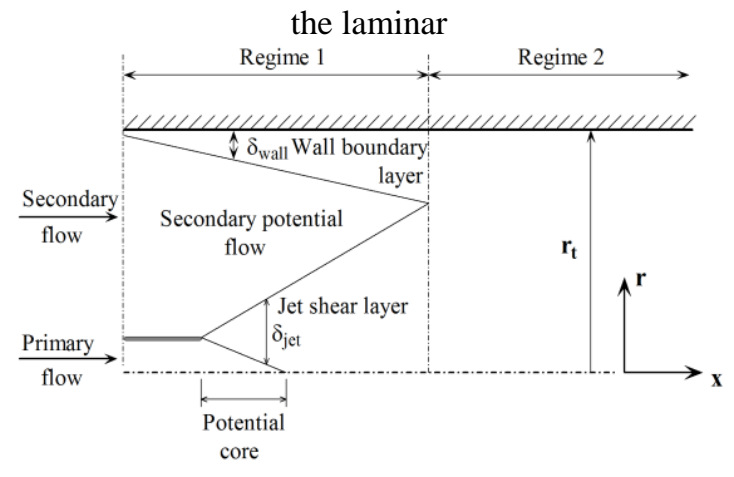

Fig. (5): Flow regions

(molecular) viscosity for solution of the momentum equation. The mixing length model predicts the turbulent viscosity as follows:

$$
\begin{gathered}
\mu_{\mathrm{t}}=\rho l_{\mathrm{m}}{ }^{2} \frac{\partial \mathrm{u}}{\partial \mathrm{r}} \\
\mu=\mu_{\mathrm{t}}+\mu_{l}
\end{gathered}
$$

The mixing length $l_{m}$ depends on the flow type and its location in the duct. For the motive and suction nozzles, the turbulence is driven by the wall. Thus, the turbulent wall layer grows in the axial direction until it fills the entire cross-section of the domain. For the mixing section, the wall layer is important as well as the shear layer in which the motive and suction flows mix. As sown in Fig. (5), both these layers grow into the undisturbed region of the flow until they meet. Both the wall dominated and jet shear dominated flows have distinct expressions for the mixing length.

For regime 1, according to turbulent flow theory the wall region can be subdivided into a wall sublayer, an overlap region, and an outer layer. For flow within the wall sublayer and logarithmic overlap region (inner layer), the mixing length is estimated by:

$$
l_{\mathrm{m}}=\mathrm{k}\left(\mathrm{r}_{\mathrm{t}}-\mathrm{r}\right)\left[1-\exp \left(\frac{\left.\left(\mathrm{r}_{\mathrm{t}}-\mathrm{r}\right)\left(\rho \tau_{\mathrm{w}}\right)^{1 / 2}\right)}{\mathrm{A}_{\mathrm{o}} \mu}\right)\right]
$$

where $\mathrm{k}=0.6$ and $\mathrm{A}_{\mathrm{o}}=26$

For the outer layer of the region, the mixing length is given by:

$l_{m}=0.09 \delta_{\text {wall }}$

The transition between the inner and outer layer occurs when the mixing length predicted by equation (29) first exceeds the value of the mixing length predicted by equation (30). For the jet region, a constant mixing length proportional to layer thickness is also used:

$l_{m}=\mathrm{k}_{\mathrm{o}} \delta_{\text {jet }}$, where, $\mathrm{k}_{\mathrm{o}}=0.08$

In the regions that are still undisturbed by turbulent shear, a mixing length of zero is used. The jet region expands with the mixing process into the two undisturbed regions. The wall region also grows into the undisturbed region and eventually meets the jet. It is assumed that after this point the thickness of the wall region and jet region remain constant. Although it is known that the wall eventually dominates the flow far downstream (jet gradually dissipates), the ejector mixing section and diffuser is not long enough to where this effect is appreciable. Thus the assumption of constant thickness after the meeting point is justified.

For regime 2, the mixing length is estimated in the wall sublayer and logarithmic overlap region (inner layer) using Eqn. (29). However, in the outer layer the mixing length is given by:

$$
\begin{aligned}
& 1_{\mathrm{mj}}=0.08 \delta_{\text {jet }} \\
& 1_{\mathrm{mb}}=0.6 \mathrm{~b}\left[1-\exp \left(\frac{\left.\mathrm{b}\left(\rho \tau_{\mathrm{w}}\right)^{1 / 2}\right)}{26 \mu}\right)\right] \\
& 1_{\mathrm{m}}=\frac{1_{\mathrm{mb}}-1_{\mathrm{mj}}}{\left(\mathrm{r}_{\mathrm{t}}-\mathrm{b}\right)-\delta_{\text {jet }}}\left(\mathrm{r}-\delta_{\text {jet }}\right)+1_{\mathrm{mj}}
\end{aligned}
$$

The "change-point" $b$, is the point at which the viscosity model predicts a larger value of $l_{m}$ than $\left(0.09 \delta_{\text {wall }}\right)$.

\subsection{Transformed Coordinates}

The final transformation converts the nondimensional form of conservation equations to a bodyfitted coordinate system. The following transformation for $x$ and $r$ is used:

$$
\begin{aligned}
& \overline{\mathrm{x}}=\mathrm{x} \quad \text { and } \quad \overline{\mathrm{r}}=\frac{\mathrm{r}-\mathrm{r}_{\mathrm{b}}}{\mathrm{r}_{\mathrm{t}}-\mathrm{r}_{\mathrm{b}}} \\
& \frac{\partial}{\partial \mathrm{x}}=\frac{\partial}{\partial \overline{\mathrm{x}}}-\frac{\overline{\mathrm{r}}\left(\mathrm{r}_{\mathrm{t}}^{\prime}-\mathrm{r}_{\mathrm{b}}^{\prime}\right)+\mathrm{r}_{\mathrm{b}}^{\prime}}{\mathrm{r}_{\mathrm{t}}-\mathrm{r}_{\mathrm{b}}} \frac{\partial}{\partial \overline{\mathrm{r}}}, \frac{\partial}{\partial \mathrm{r}}=\frac{1}{\mathrm{r}_{\mathrm{t}}-\mathrm{r}_{\mathrm{b}}} \frac{\partial}{\partial \overline{\mathrm{r}}}
\end{aligned}
$$

Where $r_{b}$ and $r_{t}$ represent the bottom and top boundaries of the domain respectively. Thus the radial domain is always between $0-1$. These boundaries are functions of the axial distance, $x$, and thus their derivatives given in equation (33) represent the slope of the top and bottom boundaries.

$$
\begin{aligned}
& r_{t}^{\prime}=\frac{d r_{t}}{d x} \quad: \quad r_{b}^{\prime}=\frac{d r_{b}}{d x} \\
& r_{d}=r_{t}-r_{b}: \quad r_{d}^{\prime}=r_{t}^{\prime}-r_{b}^{\prime}
\end{aligned}
$$

The transformation thus converts a nonrectangular grid in the physical domain to a rectangular one in the computational domain, as shown in Fig. (6), and greatly facilitates the process of discretization and computer solution. Note that the $*$ notation used in equations (7-10) has been dropped for clarity with the assumption that all variables are already dimensionless. After performing the substitutions, these equations become as follows [13]:

$$
\begin{aligned}
& \frac{\partial}{\partial \bar{x}}\left[r_{d}\left(\overline{r_{d}}+r_{b}\right) \alpha \rho u\right]-\frac{\partial}{\partial \bar{r}}\left[\left(\overline{r r}_{d}^{\prime}+r_{b}^{\prime}\right)\left(\bar{r}_{d}+r_{b}\right) \alpha \rho u\right] \\
& +\frac{\partial}{\partial \bar{r}}\left[\left(\overline{r_{r}}{ }_{d}+r_{b}\right) \alpha \rho v\right]=\left(\overline{r_{d}^{2}}+r_{b} r_{d}\right) \Gamma
\end{aligned}
$$




$$
\begin{aligned}
& \frac{\partial}{\partial \overline{\mathbf{x}}}\left[\left(\overline{\mathbf{r r}}_{\mathrm{d}}^{2}+\mathrm{r}_{\mathrm{b}} \mathrm{r}_{\mathrm{d}}\right) \alpha \rho \mathrm{u}^{2}\right]+\frac{\partial}{\partial \overline{\mathbf{r}}}\left[\left(\overline{\mathrm{rr}}_{\mathrm{d}}+\mathrm{r}_{\mathrm{b}}\right) \alpha \rho \mathrm{uv}\right] \\
& -\frac{\partial}{\partial \overline{\mathrm{r}}}\left[\left(\overline{\mathrm{rr}}_{\mathrm{d}}^{\prime}+\mathrm{r}_{\mathrm{b}}^{\prime}\right)\left(\overline{\mathrm{rr}}_{\mathrm{d}}+\mathrm{r}_{\mathrm{b}}\right) \alpha \rho \mathrm{u}^{2}\right]=-\alpha \frac{\partial}{\partial \overline{\mathrm{x}}}\left[\left(\overline{\mathrm{rr}}_{\mathrm{d}}^{2}+\mathrm{r}_{\mathrm{b}} \mathrm{r}_{\mathrm{d}}\right) \mathrm{P}\right] \\
& +\alpha \frac{\partial}{\partial \bar{r}}\left[\left(\bar{r}_{d}^{\prime}+r_{b}^{\prime}\right)\left(\bar{r}_{d}+r_{b}\right) P\right]+\frac{\partial}{\partial \bar{r}}\left[\frac{\alpha \mu\left(\bar{r}_{d}+r_{b}\right)}{\operatorname{Rer}_{d}} \frac{\partial u}{\partial \bar{r}}\right] \\
& +\left(\bar{r}_{d}^{2}+r_{b} r_{d}\right)(F x+M x) \\
& \frac{\partial}{\partial \overline{\mathbf{x}}}\left[\left(\overline{\mathrm{rr}}_{\mathrm{d}}^{2}+\mathrm{r}_{\mathrm{b}} \mathrm{r}_{\mathrm{d}}\right) \alpha \rho \mathrm{uv}\right]-\frac{\partial}{\partial \overline{\mathrm{r}}}\left[\left(\overline{\mathrm{rr}}_{\mathrm{d}}^{\prime}+\mathrm{r}_{\mathrm{b}}^{\prime}\right)\left(\overline{\mathrm{rr}_{\mathrm{d}}}+\mathrm{r}_{\mathrm{b}}\right) \alpha \rho \mathrm{uv}\right] \\
& +\frac{\partial}{\partial \overline{\mathrm{r}}}\left[\left(\overline{\mathrm{rr}}_{\mathrm{d}}+\mathrm{r}_{\mathrm{b}}\right) \alpha \rho \mathrm{v}^{2}\right]=\frac{\partial}{\partial \overline{\mathrm{r}}}\left[\frac{2 \alpha \mu\left(\overline{\mathrm{rr}}_{\mathrm{d}}+\mathrm{r}_{\mathrm{b}}\right)}{\operatorname{Rer}_{\mathrm{d}}} \frac{\partial \mathrm{v}}{\partial \overline{\mathrm{r}}}\right] \\
& +\frac{\partial}{\partial \bar{x}}\left[\frac{\alpha \mu\left(\overline{r r}_{d}+r_{b}\right)}{\operatorname{Re}} \frac{\partial u}{\partial \bar{r}}\right]+\left(\overline{\operatorname{rr}}_{d}^{2}+r_{b} r_{d}\right)\left(F_{r}+M r\right) \\
& -\left(\overline{\mathrm{rr}}_{\mathrm{d}}+\mathrm{r}_{\mathrm{b}}\right) \alpha \frac{\partial \mathrm{P}}{\partial \overline{\mathrm{r}}}-\frac{\partial}{\partial \overline{\mathrm{r}}}\left[\frac{\alpha \mu\left(\overline{\mathrm{r}}_{\mathrm{d}}+\mathrm{r}_{\mathrm{b}}\right)\left(\overline{\mathrm{r}}_{\mathrm{d}}^{\prime}+\mathrm{r}_{\mathrm{b}}^{\prime}\right)}{\operatorname{Re} \mathrm{r}_{\mathrm{d}}} \frac{\partial \mathrm{u}}{\partial \overline{\mathrm{r}}}\right] \\
& -\left[\frac{2 \alpha \mu \mathrm{r}_{\mathrm{d}}}{\operatorname{Re}\left(\overline{\mathrm{rr}}_{\mathrm{d}}+\mathrm{r}_{\mathrm{b}}\right)^{2}}\left(\overline{\mathrm{rr}}_{\mathrm{d}}+\mathrm{r}_{\mathrm{b}}\right) \mathrm{v}\right] \\
& \frac{\partial}{\partial \overline{\mathrm{r}}}\left[\left(\overline{\mathrm{rr}}_{\mathrm{d}}+\mathrm{r}_{\mathrm{b}}\right) \alpha \rho \mathrm{vT}\right]-\frac{\partial}{\partial \overline{\mathrm{r}}}\left[\left(\overline{\mathrm{rr}}_{\mathrm{d}}^{\prime}+\mathrm{r}_{\mathrm{b}}^{\prime}\right)\left(\overline{\mathrm{rr}}_{\mathrm{d}}+\mathrm{r}_{\mathrm{b}}\right) \alpha \rho \mathrm{u}\right] \\
& +\frac{\partial}{\partial \overline{\mathbf{x}}}\left[\left(\overline{\operatorname{rr}}_{d}^{2}+\mathrm{r}_{b} r_{d}\right) \alpha \rho u T\right]=E c \frac{\beta u \alpha \alpha}{C p} \frac{\partial}{\partial \overline{\mathbf{x}}}\left[\left(\overline{\mathbf{r r}}_{d}^{2}+r_{b} r_{d}\right) P\right] \\
& +\frac{1}{\operatorname{Re} \operatorname{Pr}} \frac{1}{\mathrm{Cp}} \frac{\partial}{\partial \overline{\mathrm{r}}}\left[\frac{\left(\overline{\mathrm{r}}_{\mathrm{d}}+\mathrm{r}_{\mathrm{b}}\right) \alpha \mathrm{k}}{\mathrm{r}_{\mathrm{d}}} \frac{\partial \mathrm{T}}{\partial \overline{\mathrm{r}}}\right] \\
& -\mathrm{Ec} \frac{\beta \mathrm{u} \alpha \alpha}{\mathrm{Cp}} \frac{\partial}{\partial \overline{\mathrm{r}}}\left[\left(\overline{\mathrm{rr}}_{\mathrm{d}}^{\prime}+\mathrm{r}_{\mathrm{b}}^{\prime}\right)\left(\overline{\mathrm{rr}}_{\mathrm{d}}+\mathrm{r}_{\mathrm{b}}\right) \mathrm{P}\right] \\
& +\frac{\left(\overline{r r}_{d}^{2}+r_{b} r_{d}\right)}{C p}(E h t+E m t+E k e+E w t)
\end{aligned}
$$

\subsection{Wall Function Approximation}

A wall function is used to eliminate the need for a very fine grid near the wall. The wall function approximation uses a form of the universal law of the wall in which the velocity can be expressed as a function of wall shear stress and fluid properties as follows:

$$
\mathrm{u}(\mathrm{r})=\left(\frac{\tau_{\mathrm{w}}}{\rho}\right)^{(1 / 2)} \frac{1}{\mathrm{k}} \ln \left[\frac{\left(\rho \tau_{\mathrm{w}}\right)^{1 / 2}}{\mu}\left(\mathrm{r}_{\mathrm{t}}-\mathrm{r}\right)\right]+\mathrm{B}
$$

where $\mathrm{B}=5.0$ and $k=0.6$

The previous formula is valid in the log-law region of the flow, $\left(30<\left(r_{t}-r\right)^{+}<200\right)$, where:

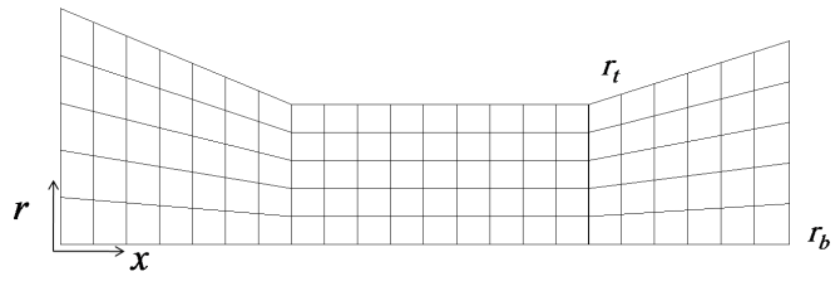

a) Grid in physical coordinates

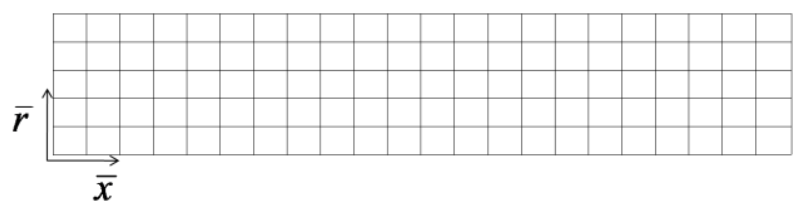

b) Grid in transformed coordinates

Fig. (6) Grid in physical and transformed coordinates

$\left(r_{\mathrm{t}}-\mathrm{r}\right)^{+}=\frac{\left(\mathrm{r}_{\mathrm{t}}-\mathrm{r}\right)\left(\rho \tau_{\mathrm{w}}\right)^{1 / 2}}{\mu}$

The velocity profile according to the law of the wall can thus be computed up to $\left(r_{t}-r\right)^{+}=200$. The velocity at this outer point then becomes the upper boundary condition for the momentum equation in which the rest of the velocity profile in the domain is computed. This procedure is straight forward except that the wall shear, $\tau_{w}$ in equation (40) is not known a priori. The wall shear force is one of the critical components of the global momentum balance which must be satisfied. Thus the procedure involves iteration on wall shear stress as follows:

1- Guess the wall shear stress $\left(\tau_{\mathrm{w}}\right)$. An educated guess in this direction can be made using the Blasius formula for pipe flow given below. For the first axial step, and the upstream value for the remaining steps.

$$
\tau_{\mathrm{w}}=0.0396 \rho^{3 / 4} \mathrm{u}_{\text {ave }}^{7 / 4} \mu^{1 / 4} \mathrm{D}^{-1 / 4}
$$

2- Use the wall function formula equation (40) to get the velocity in profile the near-wall region: $\left(30<\left(r_{t}-r\right)^{+}<200\right)$.

3- Using the wall profile as a boundary condition, solve for the remaining points in the duct by solving the momentum and continuity equations.

4- Using the entire velocity profile now obtained, and the guessed wall shear, establish whether or not the global conservation of momentum across the duct is satisfied. If it is, then the guess for wall shear in step 1 was correct. If it is not, then guess the wall shear again, return to step 2 , and repeat the calculation.

The procedure outlined above is used for the solution of the continuous (vapor) phase velocity profile. For the discontinuous (liquid) phase, the same procedure could be used computationally but it is inconvenient to do so. As the wall is approached the velocity of the discontinuous phase approaches the velocity of the 
continuous phase because both velocities are tending toward zero and because of interfacial drag. If the approximation is made that the profiles are exactly equal to each other, then the ratio of the wall shear stresses for each phase is equal to the ratio of viscosities. This enables the direct calculation of the liquid phase wall shear stress:

$$
\tau_{\mathrm{wL}}=\tau_{\mathrm{wV}} \frac{\mu_{\mathrm{L}}}{\mu_{\mathrm{V}}}
$$

The momentum equation for the second (liquid) phase can now be solved using as a boundary condition the known wall shear stress. This simplification avoids having to repeat the iterative wall function procedure for the discontinuous (liquid) phase.

\subsection{Motive Nozzle Model}

In order to calculate the maximum mass flow rate in the motive flow nozzle an initial full motive nozzle model [17] is used. In this mode the motive flow is assumed to follow the homogeneous equilibrium model (HEM) which assumes that the motive flow entrance condition is to be homogeneous with respect to velocity and in thermodynamic equilibrium from the inlet of the motive nozzle to the sonic throat. Isentropic flow conditions are assumed to prevail in the converging section of the nozzle to the throat area. The first law of thermodynamics can be solved for throat velocity:

$$
\begin{aligned}
& \mathrm{U}_{\mathrm{th}}=\left[2\left(\mathrm{~h}_{\mathrm{o}}-\mathrm{h}_{\mathrm{th}}\right)\right]^{0.5} \\
& \mathrm{~m}_{\mathrm{th}}^{\mathrm{o}}=\mathrm{U}_{\mathrm{th}} \mathrm{A}_{\mathrm{th}} \rho_{\mathrm{th}} \\
& \rho_{\mathrm{th}}=\rho_{\mathrm{TP}}=\left(\frac{\mathrm{X}}{\rho_{\mathrm{V}}}+\frac{1-\mathrm{X}}{\rho_{\mathrm{L}}}\right)^{-1}
\end{aligned}
$$

The sonic mass flow rate through the nozzle is determined by guessing the throat pressure, using the isentropic assumption and assuming the fluid is a homogeneous two-phase flow at the throat. The inlet fluid conditions are known which allows the enthalpy and specific volume at the throat to be determined and thus the throat velocity to be calculated. Throat pressure is iterated until the maximum mass flux is determined, which corresponds to the sonic (maximum) mass flow rate.

This HEM mass flux is the minimum amount of flow that can be expected to flow through a frictionless motive nozzle because this condition would have the maximum amount of vapor in the flow at the throat for these conditions. If any non-equilibrium conditions exist, less vapor would be formed and the mass flux would be greater. In reality, the motive nozzle is not frictionless, wall friction is present; therefore, the HEM model is not the absolute minimum mass flux achievable through the motive nozzle.
After the throat section, the motive flow model was developed in two different ways. First, the flow continues through the diverging section of the motive nozzle as an isentropic flow and accelerates to a supersonic jet exiting the nozzle unaffected by the nozzle back pressure. Second, the flow continues through the diverging section of the nozzle and experiences a shock which allows the nozzle exit pressure to match the nozzle back pressure. Both developments have the motive flow exiting the nozzle in thermodynamic and mechanical equilibrium.

The first development calculations proceed by knowing all of the upstream conditions, the mass flow rate, the exit area and the isentropic flow assumption. Exit pressure is guessed and because the flow is a saturated two-phase fluid the dryness fraction at the exit can be calculated from:

$$
X_{\mathrm{e}}=\frac{\left(\mathrm{S}_{\mathrm{o}}-\mathrm{S}_{\mathrm{f}}\right)}{\mathrm{S}_{\mathrm{fg}}}
$$

Once this is known, specific volume and enthalpy can be determined from the saturated liquid and vapor conditions. The first law of thermodynamics can be employed and solved from exit velocity:

$$
\mathrm{U}_{\mathrm{e}}=\left[2\left(\mathrm{~h}_{\mathrm{o}}-\mathrm{h}_{\mathrm{e}}\right)\right]^{0.5}
$$

The mass flow rate can then be calculated using:

$$
\begin{aligned}
& \mathrm{m}_{\mathrm{e}}^{\mathrm{o}}=\mathrm{U}_{\mathrm{e}} \mathrm{A}_{\mathrm{e}} \rho_{\mathrm{e}} \\
& \rho_{\mathrm{e}}=\left(\frac{\mathrm{X}_{\mathrm{e}}}{\rho_{\mathrm{V}}}+\frac{1-\mathrm{X}_{\mathrm{e}}}{\rho_{\mathrm{L}}}\right)^{-1}
\end{aligned}
$$

This mass flow rate is compared to the known sonic flow rate and exit pressure is iterated until the flow rates match to within an acceptable tolerance.

The second motive nozzle model development utilizes the saturated conditions of the flow to manipulate the first law of thermodynamics and conservation of mass to solve for the nozzle exit quality. The first law of thermodynamics Eqn. (46) is used with the definition of dryness fraction Eqn. (49) to obtain an expression for the nozzle exit velocity Eqn. (50).

$$
\begin{aligned}
& X_{e}=\frac{\left(h_{e}-h_{f e}\right)}{h_{f g e}} \\
& U_{e}=\left[2\left(h_{\mathrm{o}}-h_{f e}-X_{e} h_{f g e}\right)\right]^{0.5}
\end{aligned}
$$

This expression can be coupled with the expression for conservation of mass, Eqn. (47), to obtain the following expression: 


$$
\begin{aligned}
& \frac{1}{2}\left(\frac{\mathrm{m}^{\mathrm{o}}}{\rho_{\mathrm{fge}} \mathrm{A}_{\mathrm{e}}}\right)^{2} \mathrm{X}_{\mathrm{e}}^{2}+\left[\left(\frac{\mathrm{m}^{\mathrm{o}}}{\mathrm{A}_{\mathrm{e}}}\right)^{2} \frac{1}{\rho_{\mathrm{fe}} \rho_{\text {fge }}}+\mathrm{h}_{\mathrm{fge}}\right] \mathrm{X}_{\mathrm{e}} \\
& +\frac{1}{2}\left(\frac{\mathrm{m}^{\mathrm{o}}}{\rho_{\mathrm{fe}} \mathrm{A}_{\mathrm{e}}}\right)^{2}-\mathrm{h}_{\mathrm{o}}+\mathrm{h}_{\mathrm{fe}}=0
\end{aligned}
$$

The saturated liquid and vapor properties at the exit are known because the exit pressure is the back pressure. The equation of state and conservation of mass can then be used with dryness fraction and pressure to determine exit velocity. Of course, Eqn. (51) provides two solutions. The correct solution is easily found by determining which solution results in an increase in entropy. These methods allow the motive nozzle exit conditions to be calculated and the mixing process to be analyzed.

\subsection{Equation of State}

The Modified Benedict-Webb-Rubin (MBWR) [18] equation of state is used.

$$
\mathrm{P}=\sum_{\mathrm{n}=1}^{\mathrm{n}=9} \mathrm{a}_{\mathrm{n}} \rho^{\mathrm{n}}+\mathrm{e}^{-\left(\rho / \rho_{\mathrm{c}}\right)^{2}} \sum_{\mathrm{n}=10}^{\mathrm{n}=15} \mathrm{a}_{\mathrm{n}} \rho^{2 \mathrm{n}-17}
$$

Where,

$\mathrm{P}$ is pressure in (bar).

$\rho$ is density in (mole/liter).

$\rho_{c}$ is a reference density in (mole/liter).

$\rho_{\mathrm{c}}=5.0308$ (mole/liter).

Molecular weight of HFC-134a $=102.03$

$\mathrm{a}_{\mathrm{n}}$ are temperature dependant variables, Table (1).

$\mathrm{T}$ is temperature in $\mathrm{K}, \quad\left(\mathrm{K}={ }^{\circ} \mathrm{C}+273.15\right)$.

$\mathrm{b}_{\mathrm{i}}$ are constants, which are given in Table (2).

$\mathrm{R}$ is the gas constant.

For HFC-134a, $(\mathrm{R}=0.08314471$ (bar .Lit/(mol. K))

Table (1) Temperature dependant variables [18]

\begin{tabular}{|l|}
\hline$a_{1}=R T$ \\
\hline$a_{2}=b_{1} T+b_{2} T^{0.5}+b_{3}+b_{4} / T+b_{5} / T^{2}$ \\
\hline$a_{3}=b_{6} T+b_{7}+b_{8} / T+b_{9} / T^{2}$ \\
\hline$a_{4}=b_{10} T+b_{11}+b_{12} / T$ \\
\hline$a_{5}=b_{13}$ \\
\hline$a_{6}=b_{14} / T+b_{15} / T^{2}$ \\
\hline$a_{7}=b_{16} / T$ \\
\hline$a_{8}=b_{17} / T+b_{18} / T^{2}$ \\
\hline$a_{9}=b_{19} / T^{2}$ \\
\hline$a_{10}=b_{20} / T^{2}+b_{21} / T^{3}$ \\
\hline$a_{11}=b_{22} / T^{2}+b_{23} / T^{4}$ \\
\hline$a_{12}=b_{24} / T^{2}+b_{25} / T^{3}$ \\
\hline$a_{13}=b_{26} / T^{2}+b_{27} / T^{4}$ \\
\hline$a_{14}=b_{28} / T^{2}+b_{29} / T^{3}$ \\
\hline$a_{15}=b_{30} / T^{2}+b_{31} / T^{3}+b_{32} / T^{4}$ \\
\hline
\end{tabular}

\subsection{Sonic Velocity}

The two-phase sound speed is given by [14]:

$$
\mathrm{a}_{\mathrm{TP}}=\left(\frac{\frac{\alpha}{\rho_{\mathrm{V}}}+\frac{1-\alpha}{\rho_{\mathrm{L}}}}{\frac{\alpha}{\rho_{\mathrm{V}} \mathrm{a}_{\mathrm{V}}{ }^{2}}+\frac{1-\alpha}{\rho_{\mathrm{L}} \mathrm{a}_{\mathrm{L}}^{2}}}\right)^{(1 / 2)}
$$

(53) Where the sonic speeds for both vapor and liquid are calculated using the values given in [18]. The Mach numbers for both vapor and liquid phases are given by:

\begin{tabular}{|c|c|}
\hline $\mathrm{o} 1+9 .($ & $17-7$. \\
\hline $\begin{array}{ll}\mathrm{b} 2 & -4.0\end{array}$ & $18+3.8$ \\
\hline $6 \mathrm{E}+01$ & 19 \\
\hline$+1.3453286896 \mathrm{E}+03$ & $2 \mathrm{E}+05$ \\
\hline-1.39439 & b21 \\
\hline-3.0 & 22 \\
\hline+2.9 & $\mathrm{~b} 23+1$. \\
\hline-1.65 & b24 -1.86 \\
\hline+1.5070600 & $\mathrm{E}+04$ \\
\hline b10 & b26 \\
\hline b11 +5.4 & $\overline{E+05}$ \\
\hline b12 $-2.1132604 \mathrm{C}$ & -397282752 \\
\hline-2.6819120385 E- & b29+1.4301684480 \\
\hline b14 & b30 +8. \\
\hline-8.51 & $\begin{array}{ll}\text { b31 } & -1.7\end{array}$ \\
\hline$+2.0518825365 \mathrm{E}-01$ & \\
\hline
\end{tabular}

vapor Mach number, $\mathrm{Ma}_{\mathrm{V}}=\frac{\mathrm{u}_{\mathrm{V}}}{\mathrm{a}_{\mathrm{TP}}}$ liquid Mach number, $M a_{L}=\frac{u_{L}}{a_{T P}}$

Table (2) Coefficients of the MBWR equation of state.

\subsection{VOID FRACTION AND SLIP RATIO}

The vapor void (volume) fraction is given by [19]:

$$
\alpha_{\mathrm{V}}=\frac{1}{1+\frac{1-\mathrm{X}}{\mathrm{X}} \frac{\rho_{\mathrm{V}}}{\rho_{\mathrm{L}}} \mathrm{S}_{\mathrm{L}}}
$$

Where, the velocity slip ratio is given by Smith's correlation [19].

$$
\mathrm{S}_{\mathrm{L}}=\frac{\mathrm{u}_{\mathrm{V}}}{\mathrm{u}_{\mathrm{L}}}=\Omega+(1-\Omega)\left[\frac{\frac{\rho_{\mathrm{L}}}{\rho_{\mathrm{V}}}+\Omega\left(\frac{1-\mathrm{X}}{\mathrm{X}}\right)}{1+\Omega\left(\frac{1-\mathrm{X}}{\mathrm{X}}\right)}\right]^{\frac{1}{2}}
$$

Where $\Omega=0.4$ and $\mathrm{X}$ is the dryness fraction.

Both void fraction and slip ratio equations are only used at primary flow nozzle exit section to determine the domain initial conditions. The slip ratio and void fraction are calculated after that by solving mass, momentum and energy equations. 


\subsection{R134a Thermo-Physical Properties}

The thermodynamic properties of R134a are needed to solve this problem. A refrigerant properties database is available in [20]. These properties are correlated, incorporated and accessed through code subroutine calls. These correlations were used, however, in determining properties of both phases as their temperatures change. A set of correlations are found in literature $[20,21]$ which are simpler and faster to compute but these correlations do not cover the whole required properties.

\subsection{Solution Procedure}

The general procedure the solution takes for each downstream run is shown in Fig. (7)

\section{MODEL VALIDATION}

In order to extend the theoretical study, the model must be firstly validated. The model has been tested against published experimental and theoretical results for constant area mixing section of [13]. It is evident from Fig. (8), that the present predicted pressure distribution and the experimental one of [13] are in closer agreement than the predicted and experimental of [13]. Furthermore, Figs. (9\&10) show comparisons between present predictions and experiments for the shown mixing sections of [7\&10]. The comparisons showed acceptable agreement. The little discrepancy of the results may be due to the present model assumptions. A Comparison between predicted centerline saturation temperature distribution and published experimental data of [22] is shown in Fig. (11). In spite of the quite difference, the predicted profile is still in reasonable agreement with the experimental one.

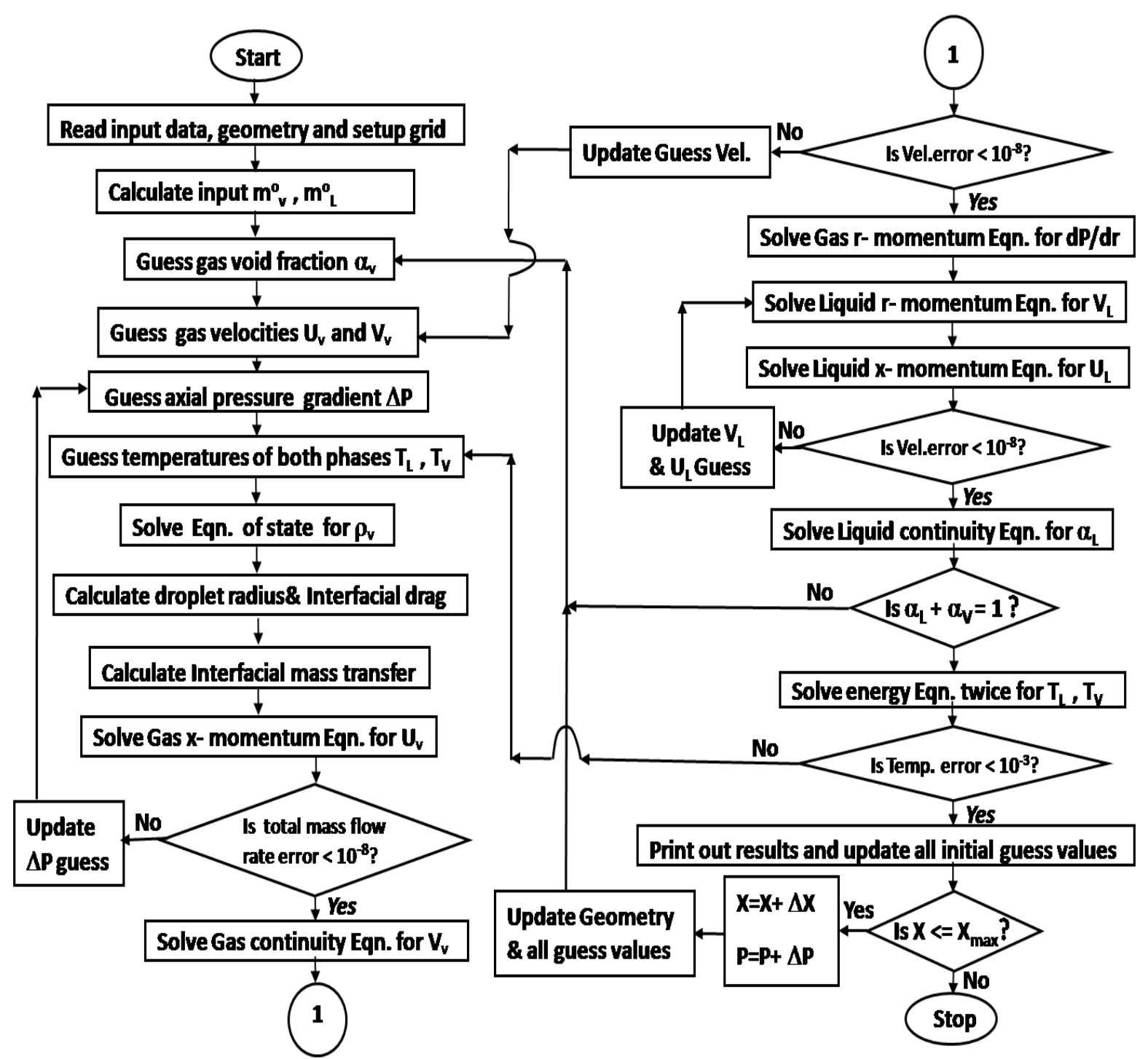

Fig. (7) Solution procedure flow chart 


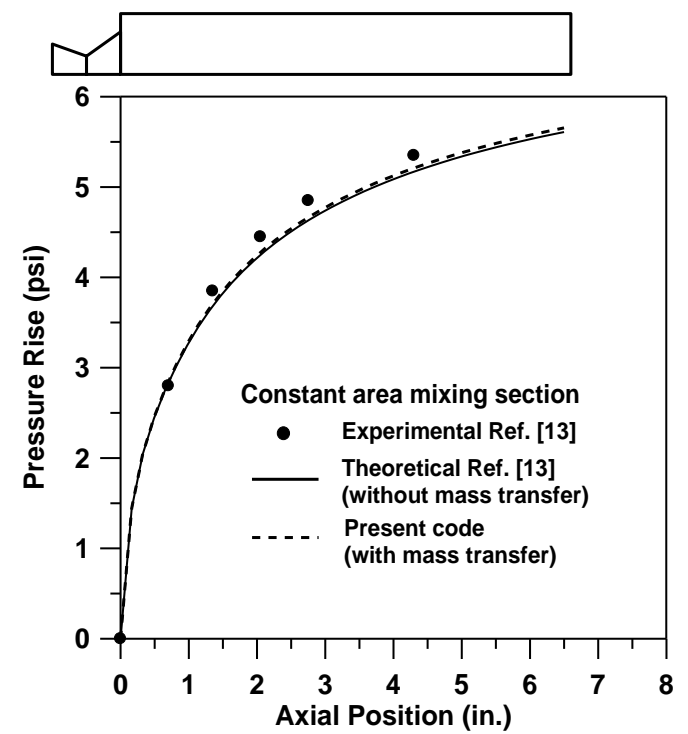

Fig. (8): Comparison between predicted wall static pressure rise distributions and published theoretical and experimental data, Ref. [13].

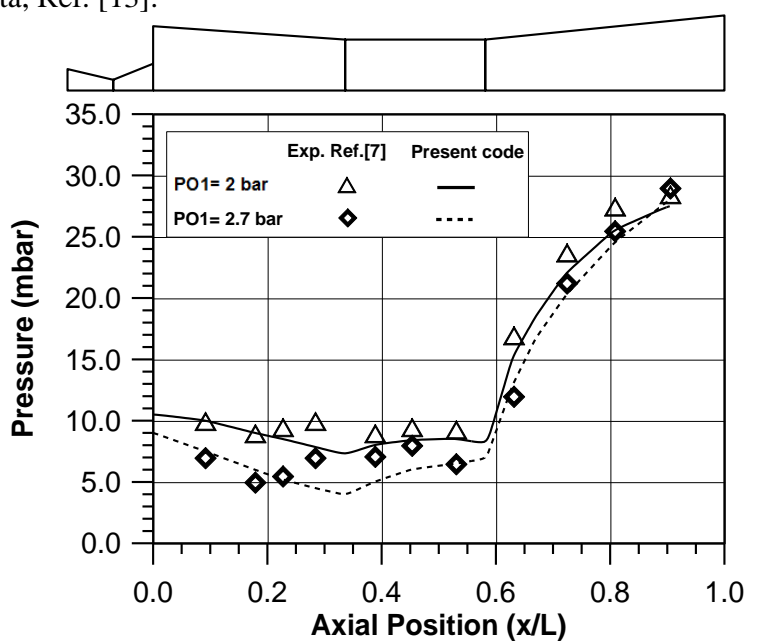

Fig. (9): Comparison between predicted wall static pressure distributions and published experimental data, Ref. [7], at two different stagnation pressures of primary flow.

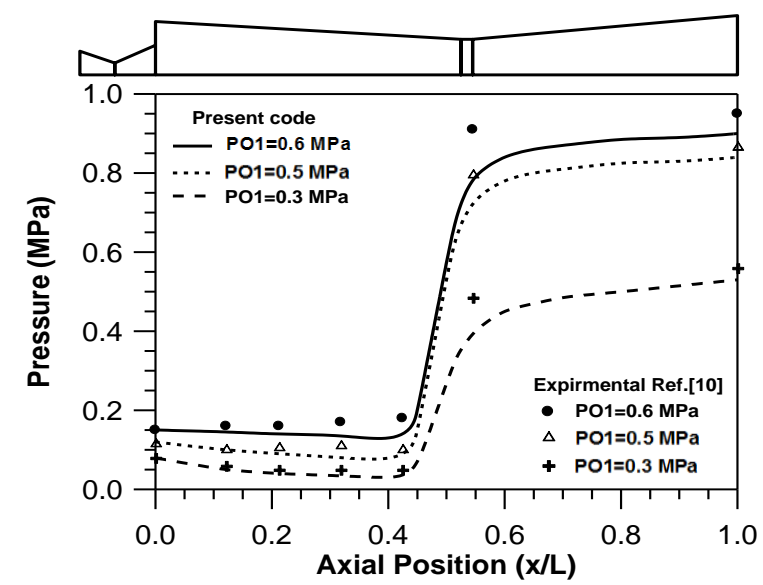

Fig. (10): Comparison between predicted wall static pressure distributions and published experimental data, Ref. [10] at different stagnation pressures of primary flow.

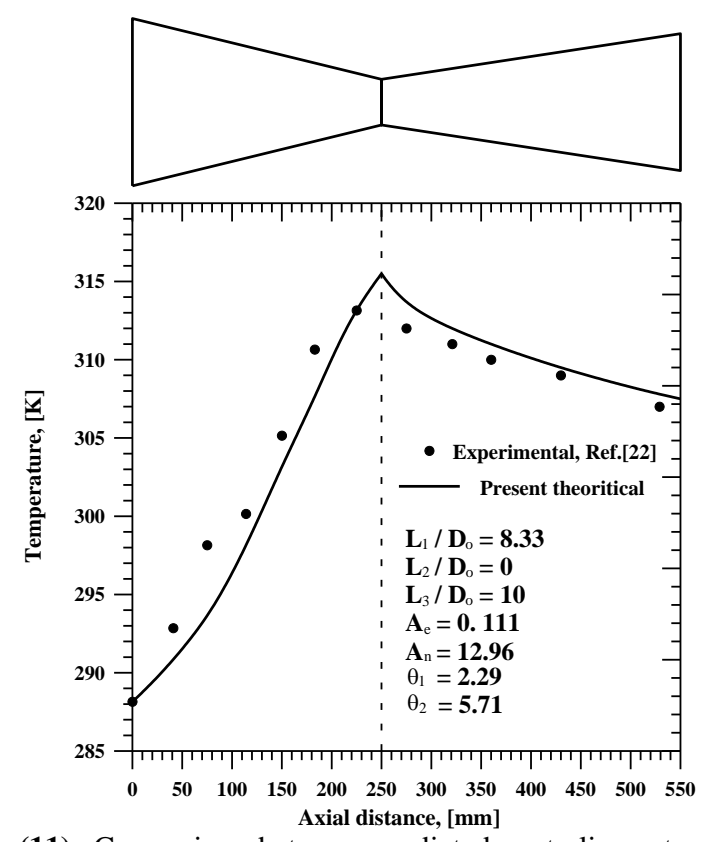

Fig. (11): Comparison between predicted centerline saturation temperature distribution and published experimental data, Ref. [22], $\varepsilon=0.53, \phi=10, \psi=0.0049, \lambda=1.22$.

\section{4- RESULTS}

After validation, the flow model is extended to investigate the effect of different parameters on ejector performance. All results are given for $\theta_{1}=6^{\circ}, \theta_{2}=5^{\circ}, A_{e}$ $=1.93$ and $A_{n}=3.07$. The effect of dryness fraction, $X_{0}$, of motive flow on the static pressure distribution for mass flow ratio, $\varepsilon=3$, at five different values of $X_{o}$ is depicted in Fig. (12). However, the suction flow is saturated vapor. An increase in the dryness fraction results in a decrease in the static pressure and consequently a lower ejector exit pressure. Figure (13) shows the effect of mass flow ratio on the static pressure distribution for inlet dryness fraction $X_{o}=0.26$. The ejector exit pressure is increased by decreasing the mass flow ratio which may be due to decreasing the average velocity of the flow. Figures (14 $\& 15)$ indicate the effect of convergent and constant mixing section lengths on static pressure coefficient. It is evident that static pressure is greatly affected not only by the operational parameters but also by the geometrical ones. The static pressure distribution together with the velocity distribution shown in figure (16) can decide if the given geometry is suitable for mixing to completely take place or not. It is desired to completely mix both flows and trying to increase the ejector exit pressure as possible at the same time. This will consequently enhance the ejector efficiency. Fig. (17) illustrates the variation of vapor void fraction, dryness fraction and droplet diameter along the ejector length. Mixing phenomena is made clear showing that, at $\mathrm{x} / \mathrm{L}=0.5$ for instance, if condensation took place there will be an increase in droplet diameter coupled with a decrease in both dryness and vapor void fractions. The contours of dryness fraction, vapor void fraction, droplet diameter, vapor temperature and liquid temperature are shown in figures $(18-22)$ for $\mathrm{L}_{1} / \mathrm{D}_{\mathrm{o}}=1.12, \mathrm{~L}_{2} / \mathrm{D}_{\mathrm{o}}=0.56$ and $\mathrm{L}_{3} / \mathrm{D}_{\mathrm{o}}=1.12$. 
The condensation is seen to be dominant in the contact

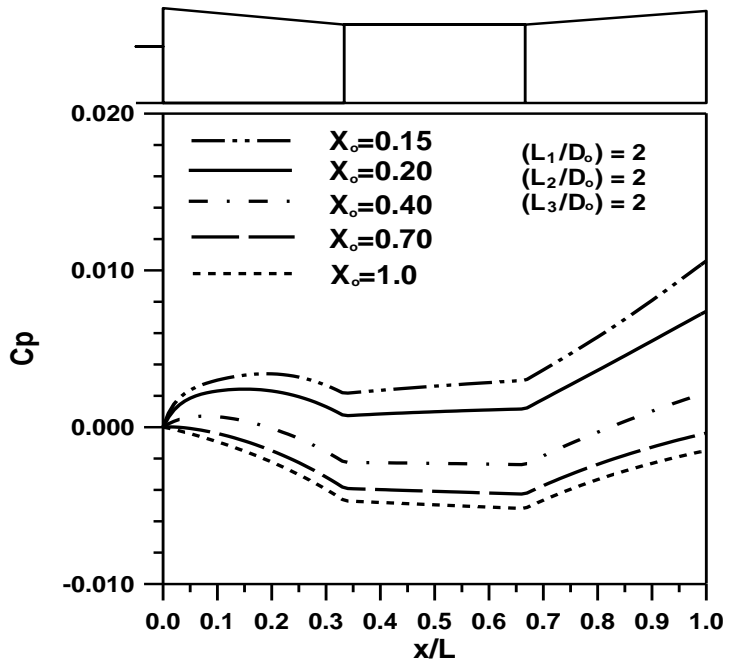

Fig. (12): Effect of dryness fraction on static pressure coefficient distributions, $\varepsilon=3, \psi=0.48$ and $\mathrm{Cp}_{\mathrm{o}}=0.15$

region between the mixing flows. Figure (23) shows that the ejector efficiency is optimum (maximum) at certain values of mass flow ratios and that ejector efficiency is greatly affected by the convergent mixing section length. The efficiency peak points are connected with a curve to allow for correlating the efficiency in terms of operational and geometrical parameters.

\section{5- CONCLUSIONS}

The effect of compressibility and mass and momentum transfer due to phase change were considered. Inhomogeneous steady state Eulerian-Eulerian approach was used. The flow regime was dispersed liquid droplets in continuous vapor. The droplet diameter was varied. The ejector performance is assessed by optimization of the ejector efficiency in an attempt to set guide lines for design charts or correlation interconnecting both geometrical and operational parameters which will be considered in our future work. The results of this study provided useful information for ejector optimization and better understanding of the mixing process taking place inside a two-phase ejector.

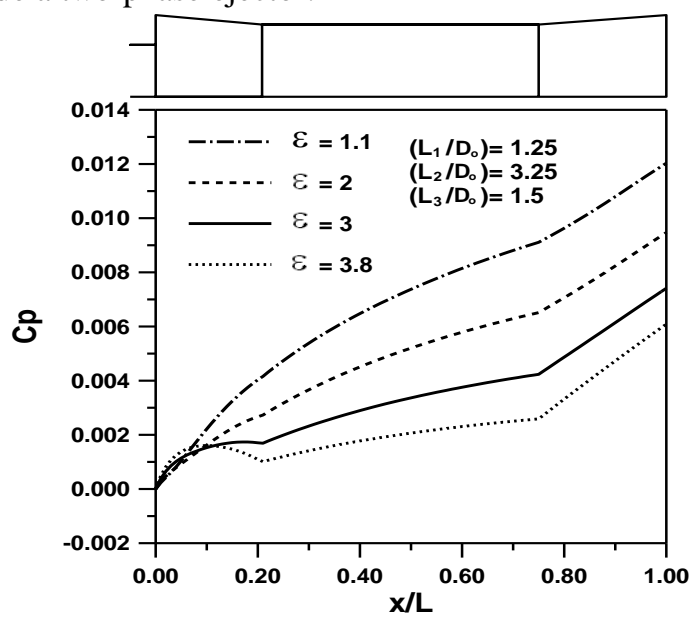

Fig. (13): Effect of mass flow ratio on static pressure coefficient distributions, $\mathrm{X}_{\mathrm{o}}=0.26, \psi=0.48$ and $\mathrm{Cp}_{\mathrm{o}}=0.15$
Fig. (14): Effect of convergent section length, $\mathrm{L}_{1}$ on static pressure coefficient distributions, $X_{0}=0.26, \varepsilon=4, \psi=$ 0.48 and $\mathrm{Cp}_{\mathrm{o}}=0.15$
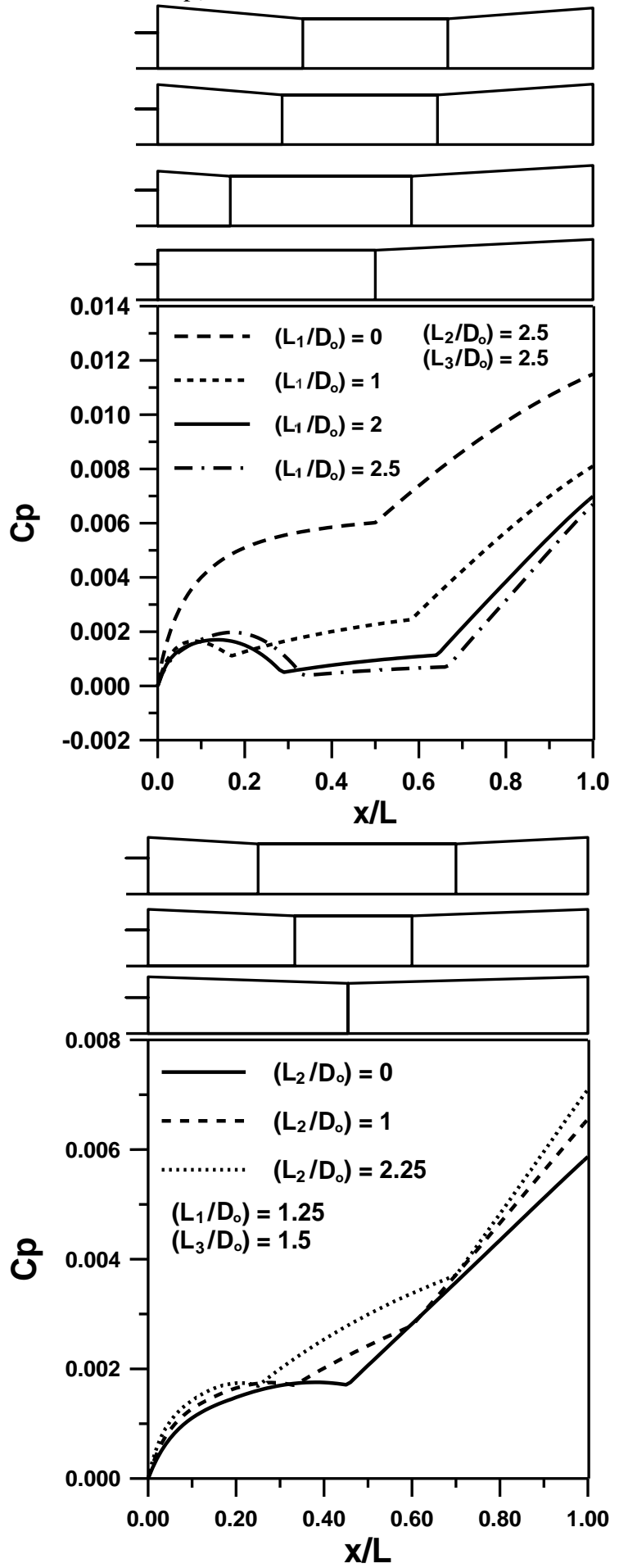

Fig. (15): Effect of constant area section length, $\mathrm{L}_{2}$ on static pressure coefficient distributions, $\mathrm{X}_{\mathrm{o}}=0.26, \varepsilon=3, \psi=0.48$ and $\mathrm{Cp}_{\mathrm{o}}=0.15$ 

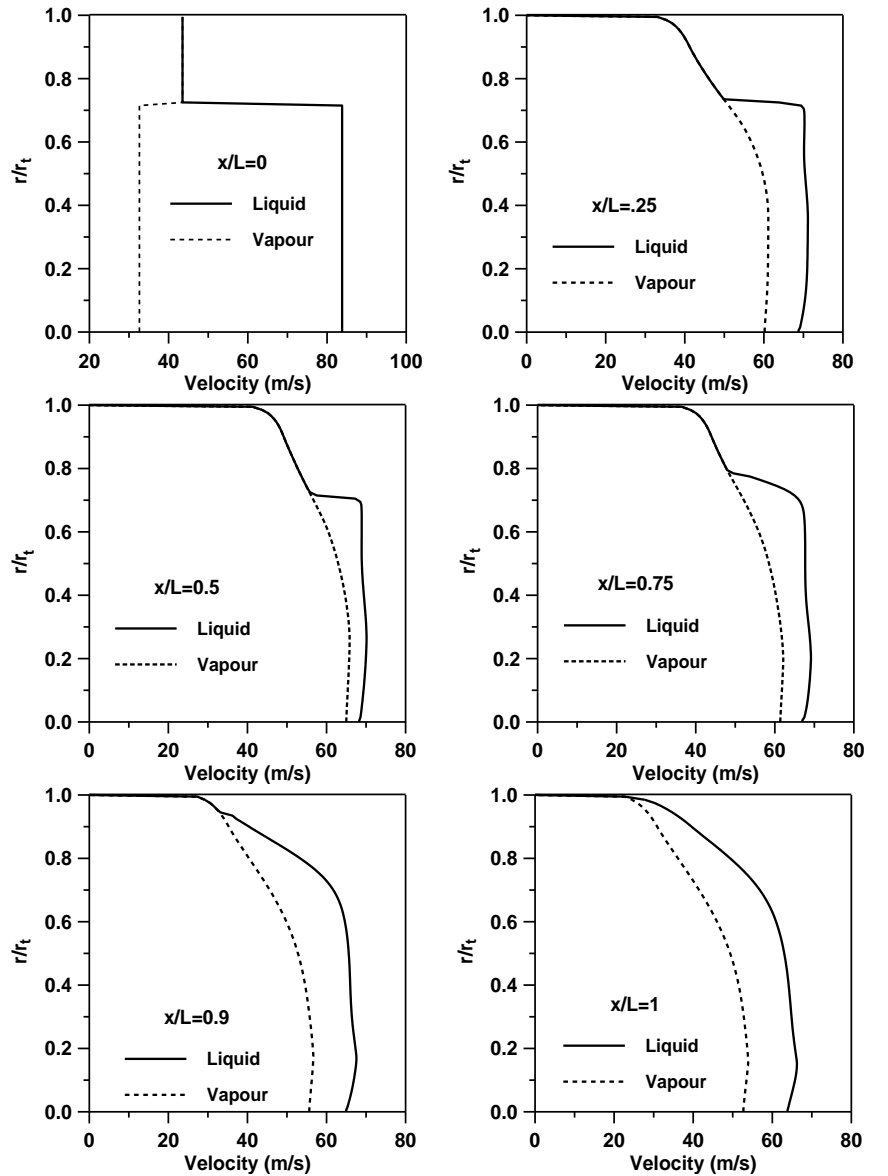

Fig. (16): Liquid and vapour axial velocity distributions along the ejector length, $\varepsilon=1.5, \mathrm{X}_{\mathrm{o}}=0.2, \psi=0.48$ and $\mathrm{Cp}_{\mathrm{o}}=0.15$
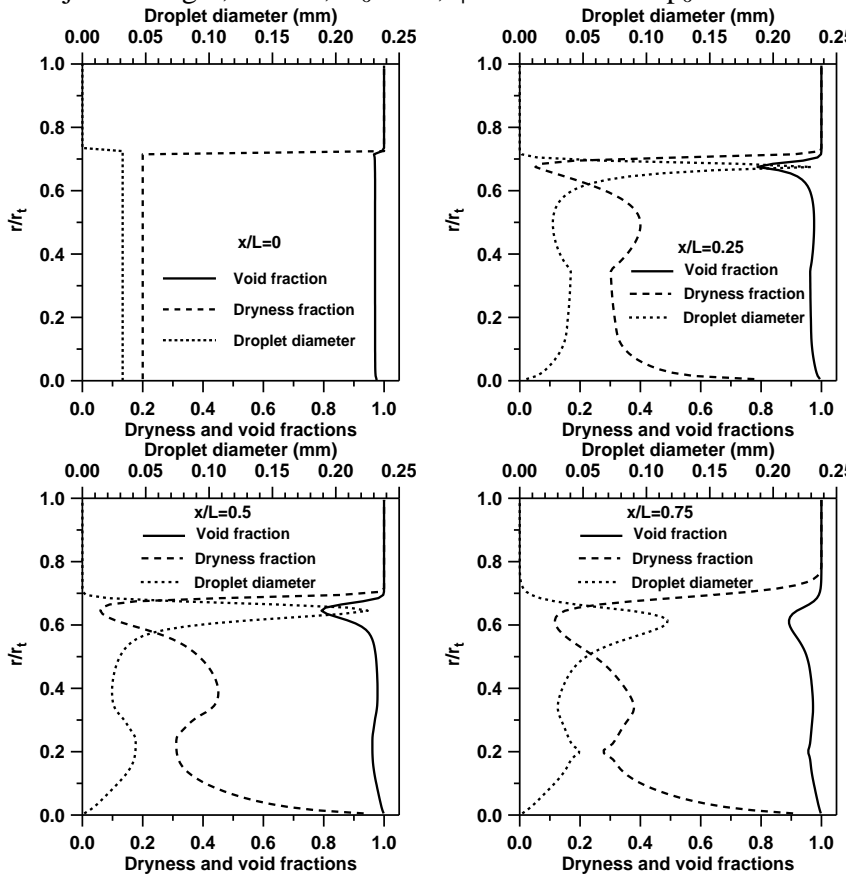
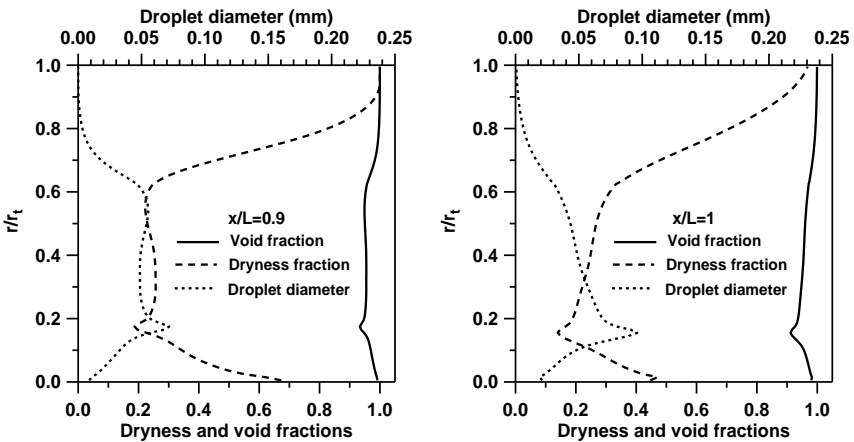

Fig. (17): Void fraction, dryness fraction and droplet diameter distributions along the ejector length, $\varepsilon=1.5, \quad \mathrm{X}_{\mathrm{o}}=0.2, \phi=1.08$ ,$\psi=0.48$ and $\mathrm{Cp}_{\mathrm{o}}=0.15$

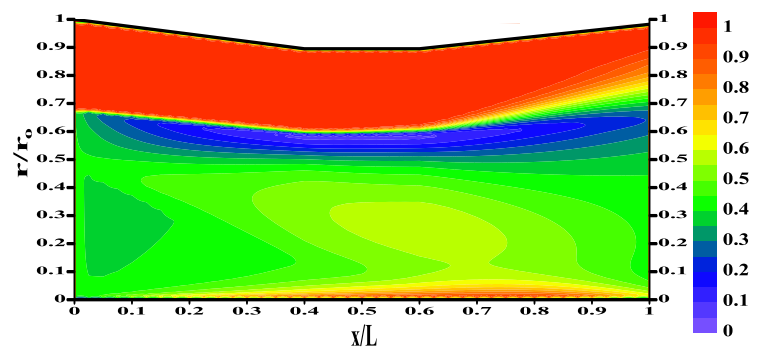

Fig. (18): Dryness fraction contours, $\varepsilon=0.1, X_{0}=0.4, \phi=1.61$, $\psi=0.127, \lambda=1.24$ and $\mathrm{Cp}_{\mathrm{o}}=0.13$

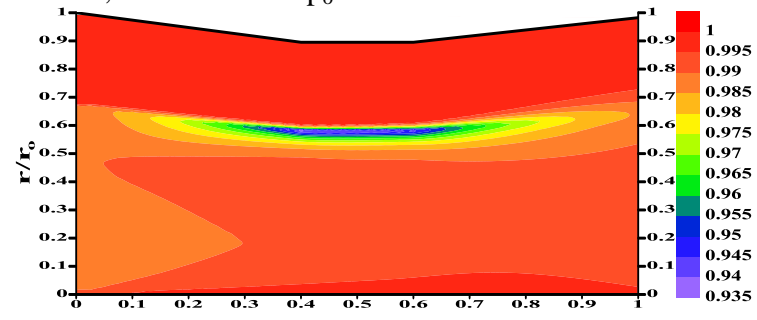

$\mathrm{x} / \mathrm{L}$

Fig. (19): Void fraction contours, $\varepsilon=0.1, X_{0}=0.4, \phi=1.61, \psi$ $=0.127, \lambda=1.24$ and $\mathrm{Cp}_{\mathrm{o}}=0.13$

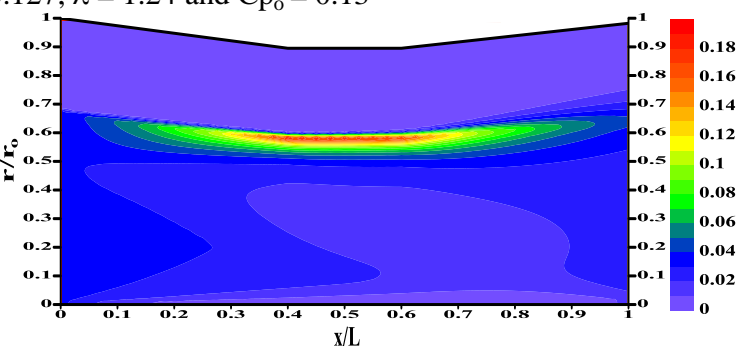

Fig. (20): Droplet diameter contours in (mm) $, \varepsilon=0.1, X_{0}=0.4$, $\phi=1.61, \psi=0.127, \lambda=1.24$ and $\mathrm{Cp}_{\mathrm{o}}=0.13$

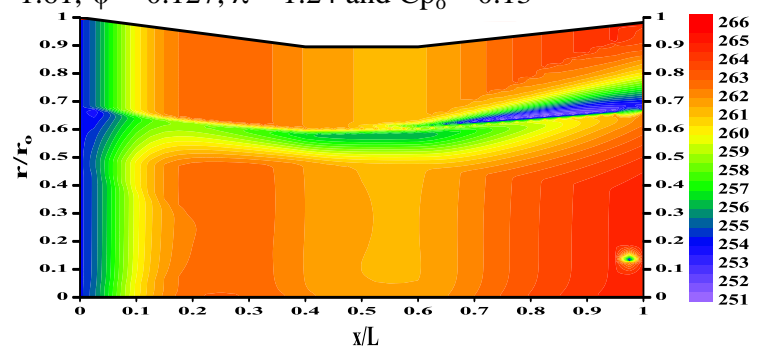

Fig. (21): Vapor temperature contours, $\varepsilon=0.1, X_{0}=0.4, \phi$ $=1.61, \psi=0.127, \lambda=1.24$ and $\mathrm{Cp}_{\mathrm{o}}=0.13$ 


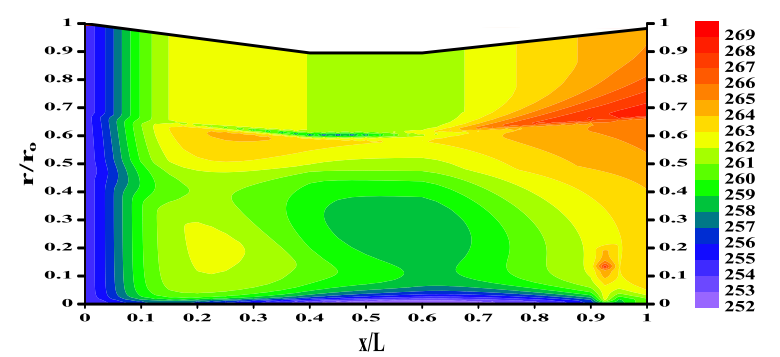

Fig. (22): Liquid temperature contours, $\varepsilon=0.1, \mathrm{X}_{0}=0.4, \phi$ $=1.61, \psi=0.127, \lambda=1.24$ and $\mathrm{Cp}_{\mathrm{o}}=0.13$

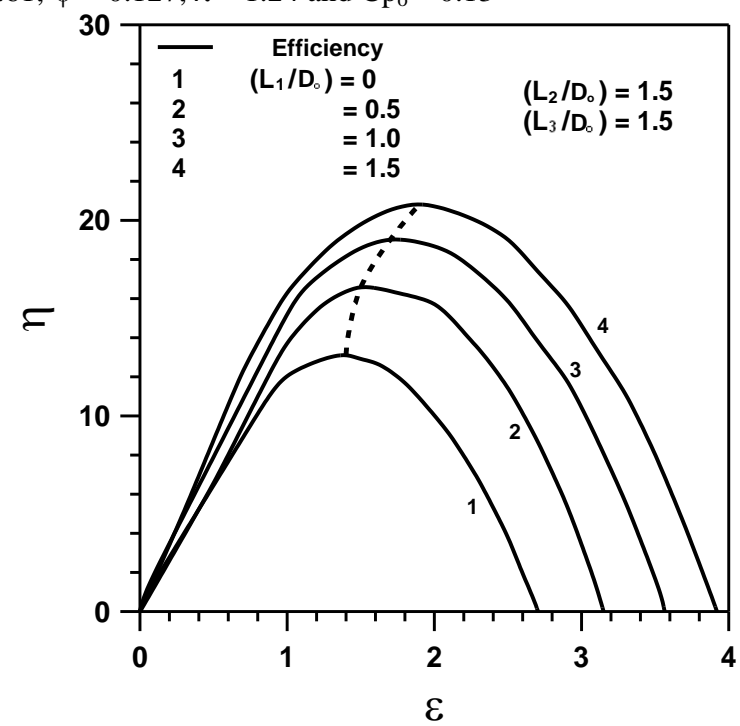

Fig. (23): Effect of mass ratio on ejector efficiency at different convergent mixing section lengths, $\mathrm{X}_{\mathrm{o}}=0.26, \psi=0.48$ and $\mathrm{Cp}_{\mathrm{o}}$ $=0.15$

\section{NOMENCLATURE}

A cross sectional area, $\left(\mathrm{m}^{2}\right)$

$A_{e} \quad=\left(\mathrm{D}_{\mathrm{o}} / \mathrm{D}_{\mathrm{e}}\right)^{2}$ (ejector area ratio), $(-)$

$A_{n} \quad=\left(\mathrm{De} / \mathrm{D}_{\mathrm{t}}\right)^{2} \quad$ (primary flow nozzle area ratio), (-)

$A_{o} \quad$ turbulence constant

$a \quad$ sonic speed, $(\mathrm{m} / \mathrm{sec})$

$C_{o} \quad$ turbulence constant

$C_{d} \quad$ drag coefficient, (-)

$\mathrm{Cp}_{\mathrm{o}}=\left(\mathrm{P}_{\mathrm{o} 1}-\mathrm{P}_{\text {ref }}\right) /\left(0.5 * \mathrm{P}_{\text {ref }} * \mathrm{U}_{\text {ref }}{ }^{2}\right)$ (stagnation pressure coefficient), (-)

$\mathrm{Cp}=\left(\mathrm{P}-\mathrm{P}_{\text {ref }}\right) /\left(0.5 * \mathrm{P}_{\text {ref }} * \mathrm{U}_{\text {ref }}^{2}\right)$ (static pressure coefficient), (-)

$D \quad$ diameter of ejector cross section at any distance $x,(\mathrm{~m})$

$D_{e} \quad$ primary flow nozzle exit diameter, (m)

$D_{o} \quad$ diameter of convergent section mixing chamber at primary flow nozzle exit, (m)

$D_{t} \quad$ primary flow nozzle throat diameter, (m)

$d \quad$ diameter of liquid droplet, (m)

$E_{h t} \quad$ interfacial heat transfer rate (either conduction or convection) between interfacial surface and the bulk phase, $\left(\mathrm{W} / \mathrm{m}^{3}\right)$

$E_{m t} \quad$ interfacial thermal energy transferred (sensible heat) due to mass transfer (evaporation or condensation)

$E_{k e}$ The interfacial kinetic energy transferred due to mass transfer, $\left(\mathrm{W} / \mathrm{m}^{3}\right)$

$E_{w t}$ The viscous dissipation produced by interfacial work transfer done by the interfacial drag force, $\left(\mathrm{W} / \mathrm{m}^{3}\right)$

Ec Eckert number resulting from nondimensionalization, (-)

$F_{x} \quad$ interfacial drag force exerted by one phase on the other in axial direction, $\left(\mathrm{N} / \mathrm{m}^{3}\right)$

$F_{r} \quad$ interfacial drag force exerted by one phase on the other in radial direction, $\left(\mathrm{N} / \mathrm{m}^{3}\right)$

$h \quad$ specific enthalpy, $(\mathrm{KJ} / \mathrm{Kg})$

$h_{f g} \quad$ latent heat, $(\mathrm{KJ} / \mathrm{Kg})$

$h_{V}, h_{L} \quad$ heat transfer coefficients for vapor and liquid respectively, $\left(\mathrm{KW} / \mathrm{m}^{2} . \mathrm{K}\right)$

$K \quad$ Thermal conductivity, (KW/m.K)

$k \quad$ turbulence constant

$k_{o} \quad$ turbulence constant

$l_{m} \quad$ mixing length, (m)

$L_{l} \quad$ convergent mixing section length, (m)

$L_{2} \quad$ constant area mixing section length, (m)

$L_{3} \quad$ divergent section length, (m)

$L \quad=L_{1}+L_{2}+L_{3}$, total ejector length, (m)

$M a \quad$ Mach number, (-)

$M_{r} \quad$ interfacial momentum transfer gain or lost due to mass transfer in radial direction, $\left(\mathrm{N} / \mathrm{m}^{3}\right)$

$M_{x} \quad$ interfacial momentum transfer gain or lost due to mass transfer in axial direction, $\left(\mathrm{N} / \mathrm{m}^{3}\right)$

$P$ pressure, $\left(\mathrm{N} / \mathrm{m}^{2}\right)$

$\mathrm{P}_{\mathrm{o} 1} \quad$ primary flow total pressure, $\left(\mathrm{N} / \mathrm{m}^{2}\right)$

$\mathrm{P}_{\mathrm{o} 2}$ secondary flow total pressure, $\left(\mathrm{N} / \mathrm{m}^{2}\right)$

$\mathrm{P}_{03}$ ejector exit flow total pressure, $\left(\mathrm{N} / \mathrm{m}^{2}\right)$

$\mathrm{P}_{\text {ne }}$ primary flow nozzle exit pressure, $\left(\mathrm{N} / \mathrm{m}^{2}\right)$

Pr Prandtl number resulting from nondimensionalization, (-)

Re Reynold's number, (-)

$R e_{i n t} \quad$ interfacial Reynold's number, (-)

$\bar{r} \quad$ body fitted coordinate system radial distance, (-)

$r_{t} \quad$ top boundary of domain

$r_{b} \quad$ bottom boundary of domain

$r_{t}^{\prime} \quad$ slope of top boundary

$r_{b}^{\prime} \quad$ slope of bottom boundary

$r_{d} \quad$ droplet radius, $(\mathrm{m})$

ro radius of convergent section of mixing chamber at primary flow nozzle exit, (m)

$S \quad$ entropy (KJ/Kg.K)

$S_{L} \quad$ Slip ratio (ratio of vapor to liquid velocities), (-)

T Temperature, $(\mathrm{K})$ 


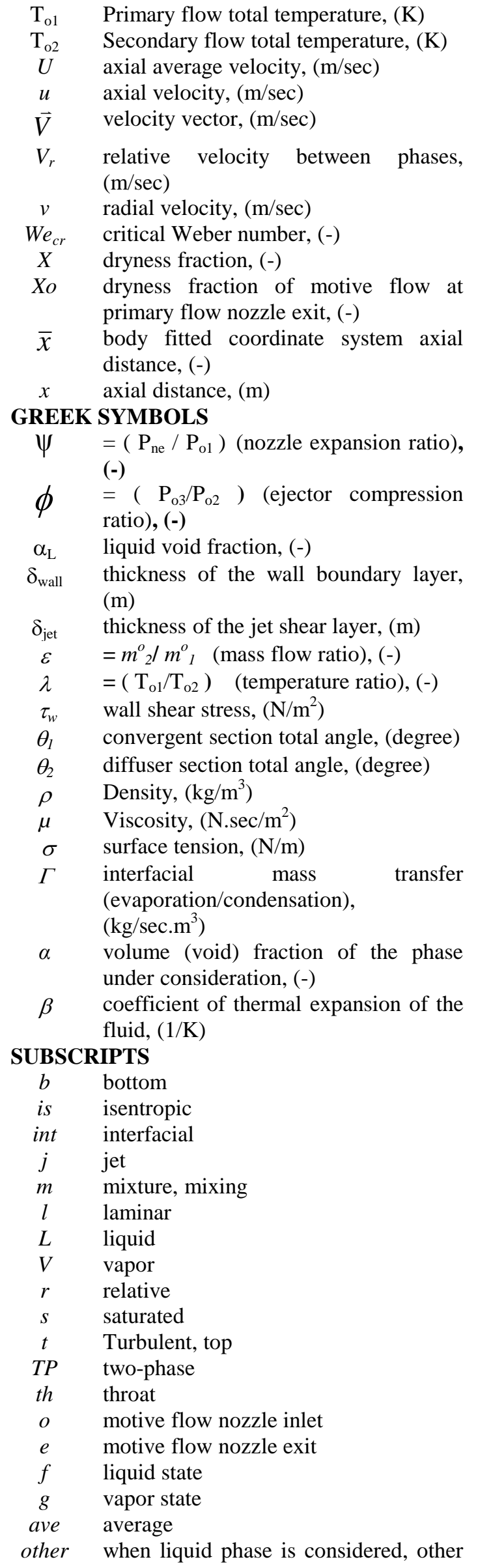

means vapor phase and when vapor phase is considered, other means liquid phase

\section{ABBREVIATIONS}

HEM homogeneous equilibrium model

$H F C$ hydroflourocarbon

$C O P$ coefficient of performance

$M B W R$ modified Benedict-Webb-Rubin equation

MAX maximum

\section{REFERENCES}

[1] Khalil A., Fatouh M., and Elgendy E., "Ejector Design and Theoretical Study of R134a Ejector Refrigeration Cycle", Int. J. Refrigeration, Vol. 34, Issue 7, pp. 1684-1698, 2011.

[2] Yang L., and Zang C., "Two-fluid Model of Refrigerant Two-phase Flow Through Short Tube Orifice”, Int. J. Refrigeration, Vol. 28, pp. 419-427, 2005.

[3] Rogdakis E. D., and Alexis G. K., "Design and Parametric Investigation of an Ejector in an Airconditioning System", Applied thermal Engineering, Vol. 20, pp. 213-226, 2000.

[4] Nabil B., and Hikmet S. A., "A Mathematical Model for Steam-driven jet Pump", Int. J. Multiphase Flow, Vol. 26, pp. 1609-1619, 2000.

[5] Yinhai Z., Wenjian C., Changyun W., and Yanzhong L., "Numerical Investigation of Geometry Parameters for Design of High Performance Ejectors", Applied thermal Engineering, Vol. 29, pp. 898-905, 2009.

[6] Rogdakis E. D., and Alexis G. K., "Investigation of Ejector Design at Optimum Operating Condition", Energy Conversion and Management, Vol. 41, pp. 1841-1849, 2000.

[7] Sriveerakul T., Aphornratana S., and Chunnanond K., "Performance Prediction of Steam Ejector Using Computational Fluid Dynamics: Part 1 Validation of the CFD Results", Int. J. of Thermal Sciences, Vol. 46, pp. 812-822, 2007.

[8] Elbel S., and Hrnjak P., "Experimental Validation of a Prototype Ejector Designed to Reduce Throttling Losses Encountered in Transcritical R744 System Operation", Int. J. Refrigeration, Vol. 31, Issue 3, pp. 411-422, 2008.

[9] Dvorak V., and Safarik P., "Supersonic Flow Structure in The entrance Part of a Mixing Chamber of 2-D Model Ejector", J. of Thermal Science, Vol. 12, No. 4, pp. 344-349, 2003.

[10] Yan J., Shao S., Liu J., and Zhang Z., "Experiment and Analysis on Performance of Steam-driven Jet Injector for District-heating System", Applied Thermal Engineering, Vol. 25, Issue 8-9, pp. 1153 $1167,2005$.

[11] Reddick C., Mercadier Y., and Ouzzane M., "Experimental Study of an Ejector Refrigeration System", International Refrigeration and Air Conditioning Conference at Purdue, July 16-19, 2012.

[12] McGoverna R. K., Bulusub K. V., Antarc M. A., and Lienhard J.H., "One-dimensional Model of an 
Optimal Ejector and Parametric Study of Ejector Efficiency", Proceedings of ECOS-The 5th Int. Conference, Perugia, Italy, June 26-29, 2012.

[13] Menegay P., "A Computational Model for TwoPhase Ejector Flow", Ph.D. Dissertation, Virginia Polytechnic Institute and State University, 1997.

[14] Elbel S., "Experimental and Analytical Investigation of A Two-Phase Ejector Used for Expansion Work Recovery in A Transcritical R744 Air-Conditioning System“, Ph.D. Dissertation, University of Illinois at Urbana-Champaign, 2007.

[15] Solbrig C. W., McFadden J. H. Lyczkowski R. W., and Hughes E. D., "Heat Transfer and Friction Correlations Required to Describe Steam-Water Behavior in Nuclear Safety Studies ", AIChE Symposium Series, Vol. 74, pp. 100-128, 1978.

[16] Cramers P. H. M. R., Beenackers A. A. C. M. and Dierendonck Van L. L., "Hydrodynamics and Mass Transfer Characteristics of a Loop-Venturi Reactor with a Downflow Liquid Jet Ejector", Chemical Engineering Science, Vol. 47, No. 13/14, pp. 35573564, 1992.

[17] Harrell, G. S., "Testing and Modeling of a TwoPhase Ejector", Ph.D. Dissertation, Virginia Polytechnic Institute and State University, 1997.
[18] Huber M. L. and McLinden M. O., "Thermodynamic Properties of R134a (1,1,1,2-tetrafluoroethane)“, International Refrigeration and Air Conditioning Conference, Purdue University, Purdue e-Pubs, Paper 184, 1992.

[19] Rice C. K., "The Effect of Void Fraction Correlation and Heat Flux Assumption on Refrigerant Charge Inventory Predictions“, ASHRAE Transactions, New York, Vol. 93, Part 1, 1987.

[20] DuPont Suva Refrigerants, "Thermodynamic Properties of HFC-134a", Miracles of Science Company, USA, 2004.

[21] SOLVAY FLUOR, "Solkane R134a Thermodynamics“,Technical Service - Refrigerants Product Bulletin NO.: T/09.04/01/E, WWW.solvayfluor.com, 2004.

[22] Dumaz P., Geffraye G., Kalitvianski V., Verloo E., Valisi M., Meloni P., Achilli A., Schilling R., Malacka M., and Trela M., "The DEEPSSI Project, Design, Testing and Modeling of Steam Injectors", Nuclear Engineering and Design, Vol. 235, pp. 233251, 2005. 